J. Linguistics 58 (2022), 111-155. C The Author(s), 2020.

Published by Cambridge University Press. This is an Open Access article, distributed under the terms of the Creative Commons Attribution licence (http://creativecommons.org/licenses/by/4.0/), which permits unrestricted re-use, distribution, and reproduction in any medium, provided the original work is properly cited.

doi: $10.1017 /$ S0022226720000407

\title{
Resultatives, goal PPs, and postverbal subjects: From Scotland to Belfast ${ }^{1}$
}

\author{
ANDREW WEIR \\ NTNU - Norwegian University of Science and Technology
}

(Received 03 July 2018; revised 14 October 2020)

This paper investigates postverbal imperative subjects (e.g., get you to school), ungrammatical in standard English but grammatical in certain contexts in dialects of Scottish and Belfast English. Henry (1995) reports that unaccusative verbs generally allow postverbal subjects in Belfast English, but in the Scottish English (ScotE) dialect considered here, only a very restricted subset of verbs allow it. Moreover, in ScotE, the preposition away can appear without an overt verb (I'll away to my bed); this also allows a postverbal subject in imperatives (away you to school). The ScotE data cast doubt on Henry's (1995) proposal that the licensor of postverbal subjects is weak agreement. The paper argues that the subjects in these constructions are actually external arguments of small clauses (of which goal PPs are taken to be a subset following, e.g., Beck \& Snyder 2001). The differences between dialects are located in the structure of resultatives; Belfast English allows Case to be assigned to the subject of small clauses in resultative constructions via a functional head endowed with a causation feature, allowing them to remain in situ in imperatives. In standard English, the causation feature is directly merged onto the verb, not allowing for Case assignment and forcing raising of the subject of the small clause. The ScotE data is argued to arise from the availability of a very 'light' verb which is realized as get in some contexts and as silence in others.

KeYwords: dialect variation, goal PPs, imperatives, resultatives, Scottish English, unaccusatives

\section{INTRODUCTION}

In her pioneering 1995 microcomparative work on Belfast English, Alison Henry discusses the fact that, for some Belfast speakers, overt imperative subjects can appear in a position following certain verbs (1).

[1] This paper has had a long gestation period and more people have probably given me useful comments and feedback on it than I can remember to list here, but I would like to thank audiences at the LAGB annual meeting in 2015, Ghent University, Simon Fraser University, and NTNU Trondheim; and Terje Lohndal and (especially) Jen Smith and Gary Thoms for very useful comments and data/intuitions. I would also like to thank two $J L$ reviewers for very useful comments on earlier drafts of this paper which led to an overhauled and I hope greatly improved analysis. Any shortcomings of course remain my own. Some early work on this paper was done at Ghent University, funded by the FWO project 009-Odysseus-Haegeman-G091409. 
(1) (a) Go you away.

(b) Run you to the telephone.

(c) Arrive you before six o'clock.

(b) Leave you now.

(e) Be elected you president.

[Belfast A; Henry 1995]

In this dialect, dubbed 'Belfast A' by Henry, only a subset of verbs allow for postverbal positioning of imperative subjects. While examples like (1) are grammatical, examples like (2) are ungrammatical in this dialect.

(2) (a) *Read you that book.

(b) *Do you your best.

(c) *Eat you up.

[Belfast A; Henry 1995]

On this basis, Henry concludes that only subjects of unaccusatives or passive verbs can be postverbal in Belfast A imperatives; the postverbal position reflects these arguments' underlying status as objects of their verbs. Henry proposes that the difference between Belfast A and standard English (StdE) can be located in a difference concerning the obligatory movement of subjects in imperative constructions.

This paper aims to elaborate the empirical and theoretical picture concerning variation between dialects of English by considering data from a dialect of Scottish English (ScotE), a variety closely related to Belfast and Ulster Englishes both historically and structurally. In the variety of Scottish English under consideration, postverbal imperative subjects are grammatical, but only with a very narrow range of verbs, narrower than in Belfast A. For example, the subject of motion get can appear after the verb and before a goal-indicating prepositional phrase (3). ${ }^{2}$

(3) (a) Get you to school.

(b) Get you over here.

(c) Get you away.

(d) Get you down those stairs.

[ScotE]

There are a very few other contexts in which a postverbal imperative subject is licit in this variety. One is with a class of verbs which I shall refer to as 'taboo off verbs, a class of 'rude' verbs of motion containing the particle off (4a). In imperatives, these verbs allow the subject to be placed between the off and an (optional) directional PP (4b).

(4) (a) He should \{clear/buzz/shove/bugger/piss/sod/fuck $\}$ off.

(b) $\{$ Clear/Buzz/Shove/Bugger/Piss/Sod/Fuck $\}$ off you (back home).

[ScotE]

[2] There appears to be a relation here with constructions available in earlier English, e.g., Hamlet's Get thee to a nunnery. I restrict myself to investigating the synchronic pattern here, though cf. Footnotes 15 and 22. 
Scottish English also permits a construction where the preposition away can appear without an overt motion verb, in a type of construction which seems familiar from other Germanic varieties or from earlier varieties of English (5). This construction can also be used as an imperative (6), and licenses post-'verbal' subjects (7) (see also Henry 1995: 58-59, 77, for a similar construction in some Belfast dialects):

(5) I'll away to school.

[ScotE]

(6) (a) Away to school.

(b) Away and see who that is at the door.

[ScotE]

(7) (a) Away you to school.

(b) Away you and see who that is at the door.

[ScotE]

However, these are the only contexts in which postverbal imperative subjects are licensed in the variety of Scottish English under investigation here. In particular, it is not the case that all unaccusative verbs allow postverbal subject placement in imperatives: the below forms, grammatical in Belfast A (1), are ungrammatical in this Scottish variety.

(8) (a) *Go you away.

(b) *Run you to the telephone.

(c) *Arrive you before six o'clock.

(d) *Leave you now.

(e) *Be elected you president.

$[\mathrm{ScotE}]$

This paper therefore seeks to answer three main questions:

(i) If the key factor licensing postverbal imperative subjects in Scottish English is not unaccusativity per se, then what is it?

(ii) Given the answer to (i), does this answer indicate a possible revision of Henry's (1995) analysis of Belfast A, and if so, how should the analysis be revised?

(iii) What factor is responsible for the variation between dialects of English concerning the licensing of postverbal imperative subjects, such that Belfast English allows them with a large number of verbs, Scottish English allows them only with a very restricted set of verbs, and standard English does not allow them at all?

In the course of addressing these questions, a fourth question will also be considered:

(iv) What is the nature of the Scottish English away construction in which a motion verb can apparently be omitted (I'll away to school/Away (you) to school!) 
The paper will propose that the answer to questions (i)-(iii) above is to be found in the structures assumed for resultative constructions in the relevant dialects, of which goal-PP constructions are assumed to be a subset (following, e.g., Beck \& Snyder 2001). Specifically, it is argued that Belfast English has a structure for resultatives involving a syntactically realized (but silent) [cause] feature on a functional head which can assign Case to the subject of the small clause within the resultative. This subject can, by dint of this, remain in situ in imperative constructions, and is not required to move to a preverbal position. By contrast, standard English lacks the functional head which assigns Case to the subject of the small clause, forcing subject movement in order to receive Case. The patterns in the 'restricted' (Scottish) variety are argued to result from spell outs of a particular kind of null verb, in conjunction with a [cause]-marked $v_{\text {ag }}$ head, which allows for the assignation of Case to the subject of PP small clauses in a very few restricted constructions. In the course of answering the questions in (i)-(iv), the paper therefore also contributes to our understanding of the syntax and semantics of unaccusative and resultative constructions generally and of goal-PP constructions more specifically.

Before proceeding, a preliminary note on data. Throughout the paper, I indicate the dialect of English from which an example is drawn (if such a label is lacking, the judgments indicated should be taken to hold across all dialects). All data for Belfast English have been taken from Henry (1995). The main source of the Scottish English data for this paper is my introspective grammaticality judgments. ${ }^{3}$ Unless specifically noted otherwise, the paper refers to this variety simply as 'Scottish English/ScotE', to avoid unwieldy repetition of 'the relevant dialect of Scottish English'. I have not aimed at empirical comprehensiveness with respect to possible dialectal variation within Scotland (or Belfast/Ulster), restricting myself to providing an analysis of the idiolect I myself have access to and making comparison with the Belfast data reported in Henry (1995). However, where I am aware of further dialectal or idiolectal variation I note this, as well as noting places where the proposed analysis is flexible enough to accommodate variation, or where it would predict variation to be ruled out.

\section{Comparing Belfast English with Scottish English}

\subsection{Henry's original analysis of Belfast $A$}

The basic data Henry (1995) seeks to account for in Belfast A is repeated in (9) from (1).
(9) (a) Go you away.
(b) Run you to the telephone.

[3] Born in 1986, male, white Scottish, middle-class, raised in Dundee/Tayside/Fife. 
(c) Arrive you before six o'clock.

(d) Leave you now.

(e) Be elected you president.

[Belfast A; Henry 1995]

There is evidence that the verb in these structures (and therefore also the subject) is structurally in a very low position. Henry shows, for example, that the verb and subject in Belfast A imperatives obligatorily appear to the right of middle-field adverbs like always.

(10) (a) Always come you here when I call you.

(b) *Come always you here when I call you.

(c) *Come you always here when I call you. [Belfast A; Henry 1995: 60]

This indicates that the verb in structures like (10a) has not inverted with the subject, at least not via movement to C (i.e. 'standard' subject-auxiliary inversion). ${ }^{4}$ Henry suggests rather that, in Belfast A imperatives, the subject remains in its basegenerated position. In the case of unaccusatives or passives, this position will be postverbal, as in (11).

(11) (a) Run you to the shops.

[Belfast A]

(b) $\left[\mathrm{CP} \ldots\left[\left[\mathrm{vP}_{\mathrm{vP}}\right.\right.\right.$ Run you $][\mathrm{PP}$ to the shops $\left.\left.]\right]\right]$

The question then arises as to why unaccusative subjects cannot remain in situ in standard English imperatives. ${ }^{5}$ Henry argues that this stems from differences between the dialects concerning the positions to which subjects must obligatorily move. Henry assumes a split IP (Pollock 1989) with separate

[4] There are dialects of both Scottish and Belfast English (Henry's 1995 Belfast B; see Jamieson 2015 for Scottish dialects) which allow verb-subject order in imperatives with any verb (including transitive verbs), and where the verb (and the subject) DOEs appear to the left of adverbs:

(i) Read you quickly that book.

[Belfast B; Henry 1995: 67]

Henry analyses such cases as involving verb movement to $\mathrm{C}$ (with the subject being in the 'standard' subject position, e.g., [Spec, TP]). This seems very plausible for both the Belfast B dialect and the relevant Scottish dialects; I will put these aside in what follows, restricting myself to the dialects which only allow postverbal imperative subjects in a restricted range of cases.

[5] Note that, on the surface, standard English imperatives sometimes appear to have postverbal subjects:

(i) (a) Stop, you.

(b) Clear off, you.

(c) Eat your dinner, you.

My assumption is that these cases are right-peripheral vocatives rather than 'true' subjects of the verb (i.e. they are parallel to Clear off, John). Note that, in the cases discussed in the main text, there is no parenthetical/comma intonation or other indication that the postverbal subjects are vocatives; see also Henry (1995: 48-49). 
functional projections hosting Tense (TP) and Agreement $\left(\operatorname{Agr}_{S} \mathrm{P}\right)$. Henry further assumes that in standard English (in declaratives), subjects obligatorily move from their vP-internal position ${ }^{6}$ to $[\mathrm{Spec}, \mathrm{TP}]$ and ultimately [Spec, $\left.\mathrm{Agr}_{\mathrm{S}} \mathrm{P}\right]$.

(12) (a) He reads that book.

(b)

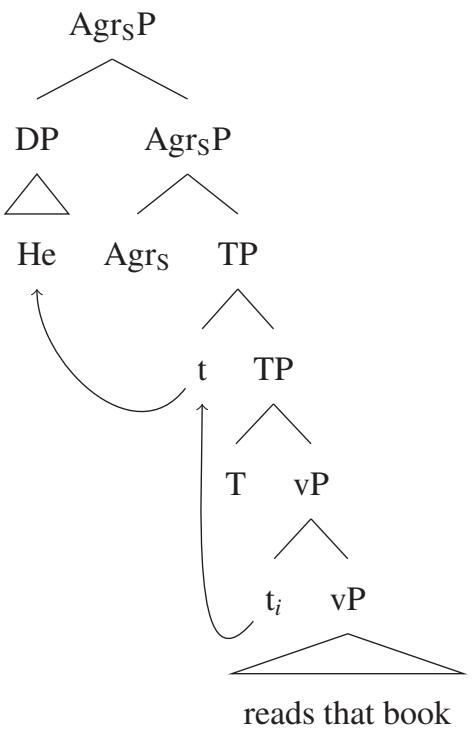

Henry argues, however, that in Belfast English, Agr $_{S}$ need not prompt movement of the subject to its Spec (at least not in the overt syntax). This is, Henry argues, independently justified given that Belfast English can show a lack of number agreement between subject and verb:

(13) (a) The eggs is cracked.

(b) These cars goes very fast.

[Belfast; Henry 1995: 16]

This is taken to be evidence for an optional lack of strong NP features on $\mathrm{Agr}_{\mathrm{S}}$, and so the subject can (optionally) raise only as far as [Spec, TP] in Belfast A:

[6] In Henry (1995) the initial subject position is [Spec, VP]; I have updated this in line with the vP hypothesis. 
(14)

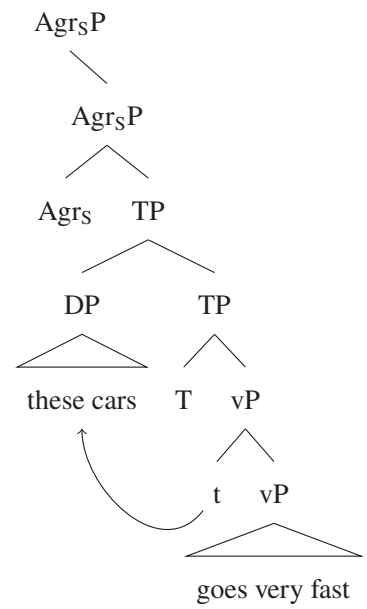

The optionality of movement into [Spec, Agrs $\mathrm{P}$ ] does not alter the word order in declaratives in Belfast A, as the subject still moves out of the vP/VP into [Spec, TP] above middle-field adverbs, auxiliaries, etc. However, Henry argues that imperatives are not specified for Tense, and so in imperatives, $\mathrm{T}$ also bears weak features (alternatively, $\mathrm{T}$ is simply not present in imperatives, as proposed by many authors, e.g., Beukema \& Coopmans 1989; Zanuttini 1996; Platzack \& Rosengren 1998; Han 2000). If $\mathrm{Agr}_{S} \mathrm{P}$ has the option of bearing weak features in Belfast English, and TP either has weak features or is not present in imperatives, then the subject is not forced to move to check any features in an imperative clause, and so need not move out of the $\mathrm{vP} / \mathrm{VP}$. In the case of a subject which starts as a complement of $\mathrm{V}-$ a passive or unaccusative subject - this results in a word order in imperatives where the subject remains in situ, in postverbal position, as shown in (15).

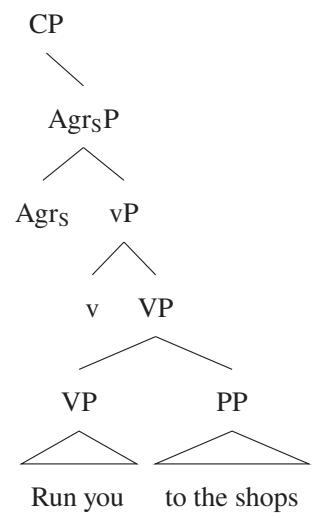


In unergatives or transitives, however, the subject is generated in the specifier of $\mathrm{vP}$; so even if the subject does not undergo movement from its base-generated position, it will still appear preverbally in imperative transitives and unergatives (16).

(16) (a) *Eat you your dinner.

[Belfast A]

(b) $\mathrm{CP}$

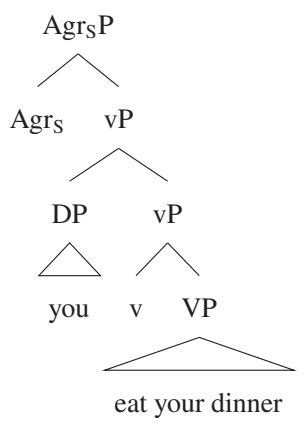

By contrast, in standard English imperatives, even if TP has weak features or is absent from the structure, $\mathrm{Agr}_{\mathrm{S}}$ is still strong, and still forces subject movement. So in standard English imperatives, subjects (if expressed) will always appear preverbally, i.e. will always move out of $\mathrm{vP}$, even if they are underlyingly complements of $\mathrm{V}$.

(17) (a) You run to the shops.

(b) *Run you to the shops.

$[* \operatorname{StdE}]$

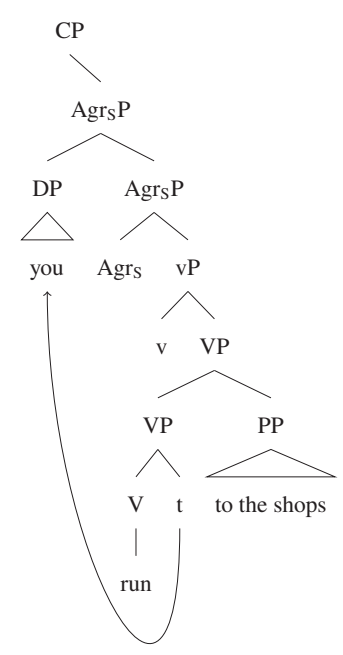

(StdE; presence of strong features on $\mathrm{Agr}_{\mathrm{S}}$ forces subject movement) 


\subsection{Challenges from Scottish English}

This analysis is attractive, particularly insofar as it explains why postverbal subject placement should only be available with unaccusative verbs in Belfast A, and provides a clear locus for the difference between Belfast A and standard English (weak agreement). It is also independently plausible to say that TP does not force subject movement in imperatives (either TP is simply missing in imperatives, or imperative TP lacks an EPP feature that would force its specifier to be filled). And the analysis can be extended, at least in part, to Scottish English; in those cases where postverbal subjects are possible in Scottish English, the verb and subject are also clearly low in the structure (below middle-field adverbs). This is shown below with VP-adjoined just ${ }^{7}$ for get and away; the pattern also extends to the 'taboo off' verbs.

(a) Just get you back to school.

(b) *Get just you back to school.

(c) *Get you just back to school.

[ScotE]

(20) (a) Just away you to school.

(b) *Away just you to school.

(c) *Away you just to school.

[ScotE]

However, Henry's (1995) analysis of Belfast English faces some challenges. One is theory-internal: separate projections for agreement, such as $\mathrm{Agr}_{S}$, were rejected in the turn to Minimalism due to their lack of interpretive import (Chomsky 1995). If this is accepted, then Henry's analysis would at least need to be updated, as if $\mathrm{Agr}_{\mathrm{S}}$ is no longer a separate projection from $\mathrm{T}$ - and if the lack of agreement in Belfast English therefore cannot be explained as the lack of strong NP features on $\mathrm{Agr}_{\mathrm{S}}-$ then the requisite parametric difference between Belfast $\mathrm{A}$ and standard English can no longer be stated; that is, it is not clear why Belfast English allows subjects to remain in situ in imperatives (but forces them to move in declaratives), while standard English forces subject movement in all cases.

However, beyond this theory-internal issue, Scottish English provides empirical grounds to doubt that (the lack of) agreement is the key determinant in the licensing

[7] In principle, the same observation can be made for Scottish English using adverbs such as never or always, but (for unclear reasons) the relevant verbs are often somewhat marginal if they appear with both such an adverb and an overt subject (regardless of whether it appears preverbally or not); this is shown for get below but the pattern extends to the other cases such as away:

(i) (a) Always get to school before the bell goes.

(b) ?You always get to school before the bell goes.

(c) ?Always get you to school before the bell goes.

However, I do not perceive any clear contrast between (i-b) and (i-c), and it is clear that trying to put the verb (and subject) BEFORE the middle-field adverb results in much stronger ungrammaticality:

(ii) ?*Get you always to school before the bell goes. 
of postverbal imperative subjects. There are speakers of Scottish English (in particular dialects spoken in the north-east) who show an agreement pattern similar to the Belfast pattern illustrated in (13), roughly speaking singular agreement with third-person plural non-pronominal subjects (the 'Northern Subject Rule'; for detail and refinements, see e.g., Smith 2000; Pietsch 2005; Adger \& Smith 2010). However, many Scottish English speakers do not accept such sentences - and crucially, there does not appear to be a correlation between acceptance of singular-agreement sentences like (13), and acceptance of low-subject imperatives like Get you to school. My own idiolect, for example, does not accept singularagreement sentences like the eggs is cracked or the boys gets to school at 9 a.m., but does allow for low-subject imperatives with the subset of verbs enumerated in Section $1 .{ }^{8}$ More crucially, acceptance of singular-agreement sentences does not seem to correlate with acceptance of low-subject imperatives with unaccusatives or motion verbs in general (i.e. forms like go you home). This is surprising if Henry's account is correct: on the fact of it, Henry's analysis predicts that systematic singular agreement with plural subjects (i.e. weak features on $\mathrm{Agr}_{\mathrm{S}}$ ) in ANY dialect of English should allow for postverbal imperative subjects (i.e. a failure of the subject to raise to $\mathrm{Agr}_{\mathrm{S}} \mathrm{P}$ in imperatives).

An anonymous reviewer points out that the above argument could rather be taken as evidence that singular agreement in Belfast and in Scots have different etiologies - and points out that the Northern Subject Rule agreement patterns are not precisely identical to the Belfast patterns (Adger \& Smith 2010) - and that it is logically possible for the 'weak $\mathrm{Agr}_{\mathrm{S}}$ ' analysis to be correct for Belfast A while some other analysis is correct for Scots. However, as the same reviewer points out, such an approach would require a disunified analysis of both agreement and of low-subject imperatives in Belfast A and in Scots; and postverbal imperatives in Scottish English show enough of a family resemblance with the Belfast pattern to make a unified analysis inviting. In particular, the basic idea that (overt) imperative subjects are forced to raise in standard English, but can (in certain constructions) remain in their base-generated position in Belfast $A$ and in Scottish English, seems like a sound one: those verbs which do allow postverbal subjects in Scottish English are motion verbs, and are plausibly therefore unaccusatives (with postverbal subjects), even if not all unaccusatives allow

[8] The argument can also be applied the other way: verbs which do not show agreement, such as beware (Fodor 1972) or come in the come VP construction (Jaeggli \& Hyams 1993), do not necessarily license postverbal subjects in Scottish English:

(i) (a) Beware (*you) of the dog.

(b) Come (*you) see me sometime.

And as an anonymous reviewer points out, many dialects of English exhibit be-leveling where singular forms of be are used with plural subjects, but there does not appear to be any particular correlation between such be-leveling and the availability of postverbal imperatives with be such as $B e$ you quiet. 
postverbal subjects in Scottish English. The evidence from verb placement with respect to middle-field adverbs also indicates that postverbal imperative subjects are in a very low position in Scottish English. In what follows, then, I propose a reanalysis of the Belfast data, which I argue can also be extended to account for the more restricted pattern seen in Scottish English, as well as identifying the locus of variation between varieties in terms of which verbs/structures allow postverbal subjects.

\section{Belfast English: a REANAlysis}

\subsection{The importance of small clauses}

I suggest that it is of key importance that almost all of the Belfast English data adduced by Henry (1995) involve the combination of an unaccusative or passive verb with a complement such as a PP, or in the case of (21c), a resultative small clause.

(21) (a) Go you to school.

(b) Run you over there.

(c) Be elected you president.

[Belfast A; Henry 1995]

Henry notes that postverbal subjects of motion verbs are, in almost all cases, ungrammatical if a PP is absent, or denotes a location rather than a goal:

(22) (a) Run you.

(b) *Run you in the garden.

(c) *Run you every day if you want to keep fit.

[Belfast A; Henry 1995: 52-53]

The only exceptions are verbs of motion which inherently specify a goal or source, such as arrive and leave, which do not require a directional PP:

(23) (a) Arrive you before six o'clock.

(b) Leave you now.

[Belfast A; Henry 1995: 53]

Henry interprets this in terms of variable unaccusativity: verbs of motion like run are analyzed as telic - and therefore unaccusative, following work by Angeliek van Hout and others (e.g., Van Hout 2004) - when combining with directional PPs, and atelic (and therefore unergative) in other cases. Henry argues that verbs such as run only allow postverbal subjects in their unaccusative frame (that is, a frame in which the subject is underlyingly a direct object of the verb). Verbs like arrive and leave are invariable unaccusatives and so always allow postverbal subjects.

I propose, however, to reanalyze the importance of the PP in these structures. In one prominent family of analyses (Hoekstra \& Mulder 1990; Beck \& Snyder 2001; Ramchand \& Svenonius 2002; Svenonius 2003, 2007, 2010; Beck 2005; Folli \& Harley 2006), goal-PP constructions such as He ran to the park have been treated as resultative constructions, where the PP denotes a small clause and 
contains an external argument; that is, the underlying structure of (24a) is something like $(24 \mathrm{~b}){ }^{9}$
(a) John ran to the park.
(b) [vP run [PP John to the park]]

On such a view, the apparent internal argument of a verb of motion combined with a goal PP would not directly be an argument of the verb. Rather, it is an external argument of the PP shell structure with which the verb combines. Further discussion of and evidence for this analysis will be given below; but if this is indeed the correct analysis of goal-PP constructions, then the generalization about Belfast English may not be that unaccusative subjects (in general) are in an underlying postverbal position in imperatives. It may rather be something like (25).

(25) In the absence of an external argument of the verb (i.e. in passives or if the main verb is unaccusative), the subject of resultative small clauses can remain in situ in Belfast English imperatives, but must raise to a higher position in standard English.

The generalization in (25) is particularly inviting in view of the example Be elected you president, grammatical in Belfast English, but not in standard English, where the subject (if expressed) is forced to raise, resulting in the order You be elected president.

I propose that the generalization in (25) can be implemented in a relatively simple way, by proposing that the grammar of transitive resultative constructions subtly differs between Belfast English and standard English. In Belfast English, a functional head intervenes between verb and small clause, the purpose of which is to semantically encode the causation relation between the two, and which assigns Case to the subject of the small clause. Such subjects therefore do not have to raise for Case in imperatives. In standard English, the feature which encodes this semantic relation is not present on a functional head between verb and small clause, but rather is merged as an affix onto the verb itself - the differing syntactic configuration resulting in different Case assignment possibilities; in standard English, subjects of small clauses must raise to get Case. In the rest of this section, I outline assumptions about the syntax and semantics of resultatives underlying such an analysis of the relevant difference between Belfast English and standard English, before returning to how Scottish English might be analyzed in Section 4.

[9] In fact, Beck (2005) assumes that such structures are control structures, i.e. [John 1 [run [PP $\mathrm{PRO}_{1}$ to the park]]]; but I am not sure that there are definite arguments against the treatment in (24), which would amount to a raising (rather than control) analysis of motion verb+PP structures. In fact, if the analysis proposed in this paper is on the right track, it can be taken as evidence for a raising analysis as at least one possible parse for goal-PP structures. 


\subsection{The syntax and semantics of resultatives}

I start by considering intransitive resultatives as in (26), exemplified with the obligatorily intransitive verb vote, and transitive resultatives as in (27), exemplified with the obligatorily transitive verb elect (see Carrier \& Randall 1992).

(26) (a) The people voted.

(b) *The people voted Kennedy.

(c) The people voted Kennedy president.

(27) (a) *The people elected.

(b) The people elected Kennedy.

(c) The people elected Kennedy president.

There are various reasons to believe that, in both (26) and (27), Kennedy president is a small clause, a constituent to the exclusion of the verb (Hoekstra 1988; contra Carrier \& Randall 1992). Scope tests, and in particular the interpretation of again (Dowty 1979; Von Stechow 1996; Beck 2005; among others), have been taken as evidence for this, as in (28).

(28) The hereditary king of Syldavia was deposed by the military; however, after the abolition of the junta, the people voted/elected him king again.

In (28), there had never previously been an election (and note that The people elected him again is a presupposition failure); again is rather modifying the constituent him king, i.e. he is once again king. Crucially, the availability of this restitutive reading tracks the syntactic position of again: it is not available in (29) (Von Stechow 1996).

(29) [Same context as (28)]

\#Again the people voted/elected him king. (only repetitive $=$ there had been an election before)

We will focus first on the case of transitive resultatives such as (27c). Even if Kennedy is the subject of a small clause headed by president, it must also be interpreted as the theme of the event of election semantically. (I return to the semantic detail of this claim below.) One way of accomplishing this would be to assume that elect takes both an object (Kennedy) and a small clause with a PRO subject controlled by Kennedy (cf. the 'Hybrid SC Analysis' discussed by Carrier \& Randall 1992; Bowers 1997).

(30) the people [vP [vP elected Kennedy $\left.{ }_{i}\right]\left[\mathrm{sC}_{\mathrm{VRO}} \mathrm{PR}_{i}\right.$ president $\left.]\right]$

However, I assume along with Kratzer (2005: 206) that PRO is not available in structures like (30): 'the known occurrences of PRO... all occur in environments where a fair amount of functional structure intervenes between it and its 
antecedent... It includes agreement morphology, which is responsible for establishing the anaphoric relationship between PRO and its antecedent'. There is no such functional structure between Kennedy and PRO in (30). Rather, I assume that Kennedy is indeed the subject of a small clause which is complement of electwhat Carrier \& Randall (1992) term the 'Binary SC analysis'.

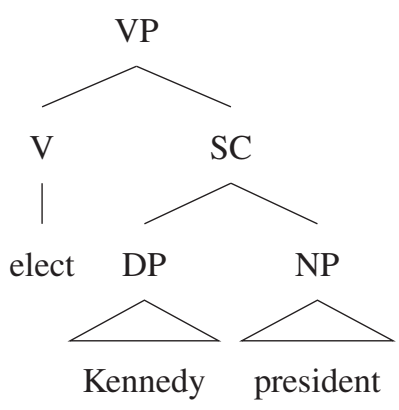

If this is right, then something has to be done about elect's obligatory transitivity. There has to be to be some way of relating transitive elect (27b) and the elect that takes a small clause (27c), by (i) reducing the valence of elect to be intransitive, (ii) ensuring that elect's logical object/theme is identified with the subject of the small clause, and (iii) ensuring that the structure overall will bear a causative/ resultative meaning. Here I propose a way of doing this, building on Kratzer's (2005) analysis of intransitive resultatives, which - as we will see - leads to positive consequences for the (re)analysis of the Belfast A data.

Suppose that the small clause Kennedy president denotes a property of states of Kennedy being president, type $\langle\mathrm{s}, \mathrm{t}\rangle$ :

$$
\llbracket \text { Kennedy president } \|=\lambda s \text {.president }(\text { Kennedy })(s)
$$

And that the verb elect is underlyingly semantically transitive, that is, it is a relation between an event and a theme (the person elected), type $\langle e, s t\rangle$ (the external/agent argument, the elector, being introduced higher in the clause by a vag head; Kratzer 1996).

(33) (a) The people elected Kennedy.

(b) $\llbracket$ elect $\rrbracket=\lambda x \cdot \lambda e \cdot \operatorname{elect}(x)(e)$

(c) $\llbracket$ elect Kennedy $\|=\lambda$ e.elect $($ Kennedy $)(e)$

The verb elect can combine with an argument like Kennedy, as in (33c), but it is not of the correct semantic type to combine with the small clause Kennedy 
president. ${ }^{10}$ Something is needed to resolve this type of mismatch. The property of states in (32) could be shifted by the application of the function in (34), for example (an adaptation of a similar proposal in Kratzer 2005: 195-196).

$$
\lambda P_{\langle\mathrm{s}, \mathrm{t}\rangle} \cdot \lambda V_{\langle\mathrm{e}, \mathrm{st}\rangle} \cdot \lambda e . \exists s . P(s) \& \text { cause }(s)(e) \& V(l x \text {.figure }(x)(s))(e)
$$

In (34), cause is a relation between events $e$ and states $s$ such that $e$ directly causes $s$, that is (roughly) that $s$ is an end-state of $e$ and if $e$ had not happened, $s$ would not hold (following Lewis 1973; Kratzer 2005); and figure is a relation between states $s$ and individuals $x$ such that $x$ is the figure (as opposed to Ground) of $s$, the salient or foregrounded entity in $s$ (cf. Talmy 1978); ' $\imath x$.figure $(x)(s)$ ' denotes the foregrounded entity in $s$.

The effect of the shift in (34) is to saturate the internal argument of a transitive verb, identifying it with the 'figure' of the small clause, and to introduce a causative relation between the event denoted by the verb and the state denoted by the small clause. This can be seen more concretely by stepping through how (34) would apply in (31). The shift would apply between the verb elect and the small clause Kennedy president, applying first to Kennedy president:

$$
\begin{aligned}
& \text { Shift in (34) applied to } \llbracket \text { Kennedy president } \rrbracket: \\
& \lambda V_{\langle\text {e,st }\rangle} \cdot \lambda e . \exists s \cdot \text { president }(\text { Kennedy })(s) \& \text { cause }(s)(e) \& \\
& V(l x . \text { figure }(x)(s))(e)
\end{aligned}
$$

The function in (35) then in turn takes the transitive verb, here elect, as its argument:

(36) Function in (35) applied to «elect $\rrbracket:$

$$
\begin{aligned}
& \lambda e . \exists s \cdot \text { president }(\operatorname{Kennedy})(s) \& \text { cause }(s)(e) \& \\
& \operatorname{elect}(l x . \text { figure }(x)(s))(e)
\end{aligned}
$$

The result is a predicate of events (i.e. the type of a intransitive verb). Those events are such that they cause a state $s$ of which $P$ holds (in this case, a state in which Kennedy is president), and they are events of electing the figure of this resultant state. In (36), the figure of the end-state caused by an event of election, in which state Kennedy is president, is picked out; it is reasonable to assume that the 'figure' in all such states is Kennedy himself. In this way, the 'figure' of the small clause can be identified with the theme of the event of election.

The shift in (34), when applied to a small clause and a verb, then does what was required: it introduces a causal relation between the event denoted by the verb and

[10] If events and states are taken to be the same type, of eventualities, then they could compose via a rule of Event(uality) Identification, as in Kratzer (1996), which would yield the below:

(i) $\lambda x . \lambda i$.elect $(x)(i) \&$ president $($ Kennedy $)(i)$

But as Kratzer (2005: 195) notes, this sort of intersective interpretation would yield an anomalous result, a function mapping every input to False, as no eventuality is both an action of election and a state. Such a composition strategy is therefore plausibly independently ruled out. 
the state denoted by the small clause, and it reduces the valency of the verb, saturating its internal argument and identifying it with the figure of the state denoted by the small clause (the end-state of the causal event).

Note that this shift, and in particular the identification of the subject of the small clause with the thematic object of the verb, leads to a slightly different outcome from Kratzer's (2005) treatment of intransitive resultatives like (37).

\section{John drank the teapot dry.}

In such a case, the apparent object (the teapot) is clearly not semantically an argument of the verb (Hoekstra 1988; Kratzer 2005), as it is not the teapot which is drunk (which is even clearer in examples like John drank the pub dry). Kratzer proposes that drink is basically intransitive (38a), and that the small clause (which denotes the state of the teapot being dry, (38b)) is shifted (38c) without saturating any internal argument of the verb, leading to the denotation in (38d).

$$
\begin{aligned}
& \text { (a) } \llbracket \text { drink } \rrbracket=\lambda e \cdot \operatorname{drink}(e) \\
& \text { (b) } \llbracket \text { the teapot dry } \rrbracket=\lambda s \cdot \operatorname{dry}(\text { teapot })(s) \\
& \text { (c) causative shift: } \lambda P P_{\langle\mathrm{s}, \mathrm{t}\rangle} \cdot \lambda e . \exists s \cdot P(s) \& \text { cause }(s)(e) \\
& \text { (Kratzer } 2005: 200, \text { slightly adapted) } \\
& \text { (d) causative shift applied to } \llbracket \text { the teapot dry } \rrbracket: \\
& \lambda e . \exists s . \operatorname{dry}(\text { teapot })(s) \& \text { cause }(s)(e)
\end{aligned}
$$

The verb drink can then combine with (38d) intersectively to deliver (39):

$$
\begin{aligned}
& \llbracket \operatorname{drink}[\text { the teapot dry] } \rrbracket=\lambda e . \exists s . \operatorname{dry}(\operatorname{teapot})(s) \& \operatorname{drink}(e) \& \\
& \text { cause }(s)(e)
\end{aligned}
$$

If the above proposals are on the right track, this predicts a difference between resultatives built on basically intransitive verbs such as drink and those built on obligatorily transitive verbs such as elect: the former do not, but the latter do identify the subject of the small clause with the theme of the event. This is a welcome conclusion already for the case of drink the teapot dry, where one does not want to identify the teapot as the theme of the drinking. It is also a welcome conclusion for transitive verbs like elect. Consider the below contrast between obligatorily intransitive vote and obligatorily transitive elect.

(40) (a) The people voted (*Kennedy).

(b) The people elected $*$ (Kennedy).

(41) (a) The people voted Kennedy president/into the White House.

(b) The people elected Kennedy president/into the White House.

(42) (a) The people voted Carter out of a job/onto the dole queue.

(b) \#The people elected Carter out of a job/onto the dole queue.

The interpretations of (41) are unsurprising on the treatments given above: there is an event of voting (respectively election) which causes Kennedy to be president/in 
the White House, and in (41b), Kennedy - the figure of the resultant state in which he is president - is the theme/patient of the election. What happens with (42), by contrast? The denotations of the verb phrases (that is, ignoring the subject/agent the people) in these cases are as below, applying the semantic rules above.

(a) $\quad$ vote Carter onto the dole queue $\rrbracket=\lambda e . \exists s$.onDoleQueue $($ Carter $)(s)$ $\& \operatorname{vote}(e) \& \operatorname{cause}(s)(e)$

(b) $\quad$ elect Carter onto the dole queue $\|=\lambda e . \exists s$.onDoleQueue $($ Carter $)(s)$ $\& \operatorname{elect}(l x$.figure $(x)(s))(e) \& \operatorname{cause}(s)(e)$

Nothing is deviant about (43a); a voting event could easily cause a state in which Carter is on the dole queue. However, (43b) describes events which have as their end-state Carter being on the dole queue and in which the figure of this end-state (Carter) was the theme of the election. Given this contradiction - the themes of events of election are the winners, not the losers - (42b) comes out contradictory/ deviant. ${ }^{11}$

\subsection{Encoding causation in syntax - in Belfast English and standard English}

Suppose that shifts such as those discussed above are available and mediate between verbs and small clauses in resultative constructions. How are these shifts encoded in grammar? One option is to assume that there are special rules of semantic composition, or type-shifting, which apply to structures like (31), where a verb composes with a predicate of states. Such a rule, for example, is proposed by Von Stechow (1995) for resultatives under the name of 'Principle R', further extended by Beck \& Snyder (2001) to goal-PP constructions. An alternative, explored by Kratzer (2005) and which I would like to adopt here, is that the shift is represented directly in the syntax, by means of a (possibly silent) head or feature with an appropriate semantics. Kratzer (2005) proposes that, in resultative constructions with intransitive verbs, an affixal morpheme [cause] appears atop the small clause (44). This morpheme has the semantics in (45a); it shifts the stative denotation of the SC (38b) into a predicate of events of causing such states to come about (45b).

[11] Note that this result means that the 'figure' predicate is required in the function that links small clause and verb; it would not be sufficient for the internal argument of a transitive verb to simply be existentially quantified in these resultative constructions, as in the putative translation below.

(i) $\llbracket$ elect Carter onto the dole queue $\rrbracket=\lambda e . \exists s . \exists x$. onDoleQueue $($ Carter $)(s) \& \quad$ (wrong) $\operatorname{elect}(x)(e) \& \operatorname{cause}(s)(e)$

Such a translation would not come out contradictory, because this simply requires someone to be the theme (i.e. the victor) of an election which causes Carter to be on the dole queue - for example, Reagan in 1980. 
(44)

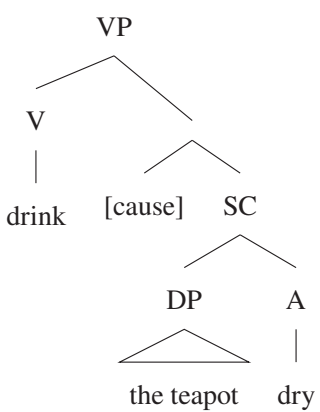

(45) (a) $\quad \llbracket[$ cause $] \rrbracket=\lambda P_{\langle\mathrm{s}, \mathrm{t}\rangle} \cdot \lambda e \cdot \exists s \cdot P(s) \& \operatorname{cause}(s)(e)$

(b) $\quad \llbracket$ [cause] the teapot dry $\rrbracket=\lambda e \cdot \exists s \cdot \operatorname{dry}($ teapot $)(s) \&$ cause $(s)(e)$

Suppose that the shift that I have proposed for transitive verbs can be encoded in a

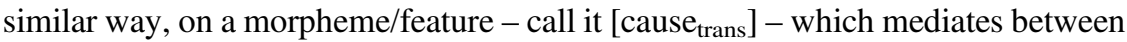
transitive verbs and small clauses.

(46)

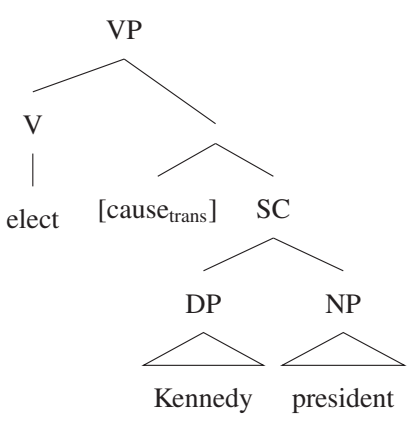

(47) (a) $\quad \llbracket\left[\right.$ cause $\left._{\text {trans }}\right] \rrbracket=\lambda P_{\langle\mathrm{s}, \mathrm{t}\rangle} \cdot \lambda V_{\langle\mathrm{e}, \mathrm{st}\rangle} \cdot \lambda e \cdot \exists s \cdot P(s) \&$ cause $(s)(e) \&$ $V(l x$.figure $(x)(s))(e)(=(34))$

(b) $\llbracket\left[\left[\right.\right.$ cause $\left._{\text {trans }}\right][$ Kennedy president $\left.]\right] \rrbracket=$ $\lambda V_{\langle e, \text { st }\rangle} \cdot \lambda e \cdot \exists s$.president (Kennedy) $(s)$ $\&$ cause $(s)(e) \& V(l x$.figure $(x)(s))(e)$

(c) $\quad$ elect $\|=\lambda x$. $\lambda e \cdot \operatorname{elect}(x)(e)$

(d) $\quad\left[\left[\right.\right.$ elect $^{[}\left[\right.$cause $\left._{\text {trans }}\right][$ Kennedy president $\left.\left.]\right]\right] \rrbracket=$ $\lambda e . \exists s$.president (Kennedy) $(s)$ $\&$ cause $(s)(e) \&$ elect $(l x$.figure $(x)(s))(e)$ $=\lambda e . \exists s \cdot$ president $($ Kennedy $)(s)$ $\&$ cause $(s)(e) \&$ elect $($ Kennedy $)(e)$ 


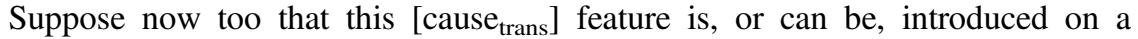
functional head which is capable of assigning accusative Case downwards to the subject of the small clause.

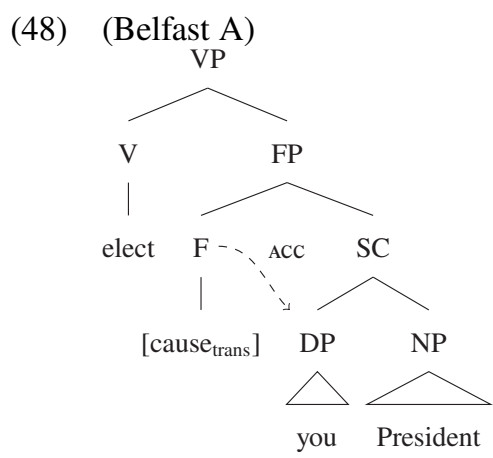

If this is possible, at least in Belfast English, then we can explain why the word order Be elected you President is grammatical in imperatives in Belfast English. The subjects in such structures - actually the arguments of the embedded small clauses, not on this view (syntactic) arguments of the verb - must raise in declaratives to satisfy the EPP (You were elected President), but in imperatives, where the EPP is by hypothesis not active, the subject need not raise, even for Case, as it has its Case needs satisfied by the functional head which hosts [cause trans $_{\text {] }}$.

What is the difference with standard English? I propose that, in standard English,

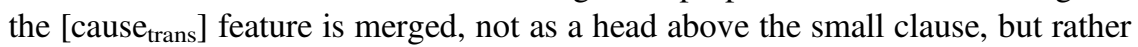
directly onto $\mathrm{V}$. This requires a reversal in the order of the arguments of [cause trans $_{\text {] }}$, but otherwise, composition can proceed unproblematically.

(49) (Standard English)

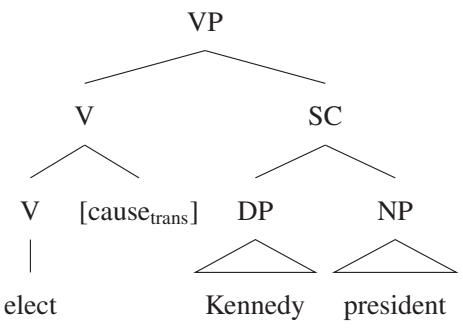

(50) (a) $\quad \llbracket\left[\right.$ cause $\left._{\text {trans }}\right] \rrbracket=\lambda V_{\langle\mathrm{e}, \mathrm{st}\rangle} \cdot \lambda P_{\langle\mathrm{s}, \mathrm{t}\rangle} \cdot \lambda e \cdot \exists s \cdot P(s) \&$ cause $(s)(e) \&$ $V(l x$.figure $(x)(s))(e)$

(b) $\quad[[(49)] \rrbracket=\lambda e . \exists s$.president $(\operatorname{Kennedy})(s) \& \operatorname{cause}(s)(e) \&$ $\operatorname{elect}(l x$.figure $(x)(s))(e)$ $=\lambda e . \exists s \cdot$ president $($ Kennedy $)(s) \&$ cause $(s)(e) \&$ elect $($ Kennedy $)(e)$ $(=(47 \mathrm{~d}))$ 
However, this structure does not contain any functional head assigning Case to the subject of the small clause Kennedy. In a passive structure, there is no other source for Case within the extended verbal projection either:

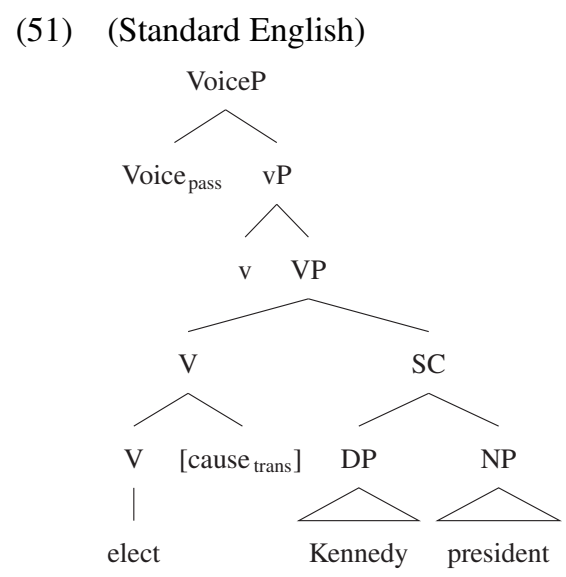

In structures like (51) in standard English, then, the subject of the small clause will have to raise for Case. In declaratives, this would be to [Spec, TP] (Kennedy was elected president). Given the grammaticality (in all Englishes) of overt-subject imperatives where the subject is preverbal (you be elected president, everybody eat their dinner, etc.), I assume that there is some preverbal functional projection also in imperatives to which the subject can move and receive Case. I remain agnostic here about what this projection is; it could be T, as in declaratives, and as Zanuttini, Pak \& Portner (2012) suggest (cf. Rupp 2007 on IP in imperatives; pace Henry 1995 and the references cited in Section 2 for the lack of TP in imperatives); if so, it would have to be a $\mathrm{T}$ exceptionally lacking the EPP-property which forces subject movement (as we do not want subject movement to this high position to be forced in Belfast A imperatives). To remain neutral on the matter here, I show this projection as FP in (52). This movement is optional in Belfast A, because the subject of the small clause can get Case in situ from the functional head hosting [cause $_{\text {trans }}$ ] as in (48); but in standard English, the requirements of the Case Filter force overt imperative subjects to raise to this higher position. ${ }^{12}$

[12] I do not think anything hinges on the precise representation of passives (auxiliary be in $\mathrm{v}$ selecting Voice $_{\text {pass }}$ ) that I employ in (52), as long as there is no source of Case for you in its base position. 
RESULTATIVES, GOAL PPS, AND POSTVERBAL SUBJECTS

(52) (a) You be elected president!

[StdE]

(b) $\quad \mathrm{CP}$

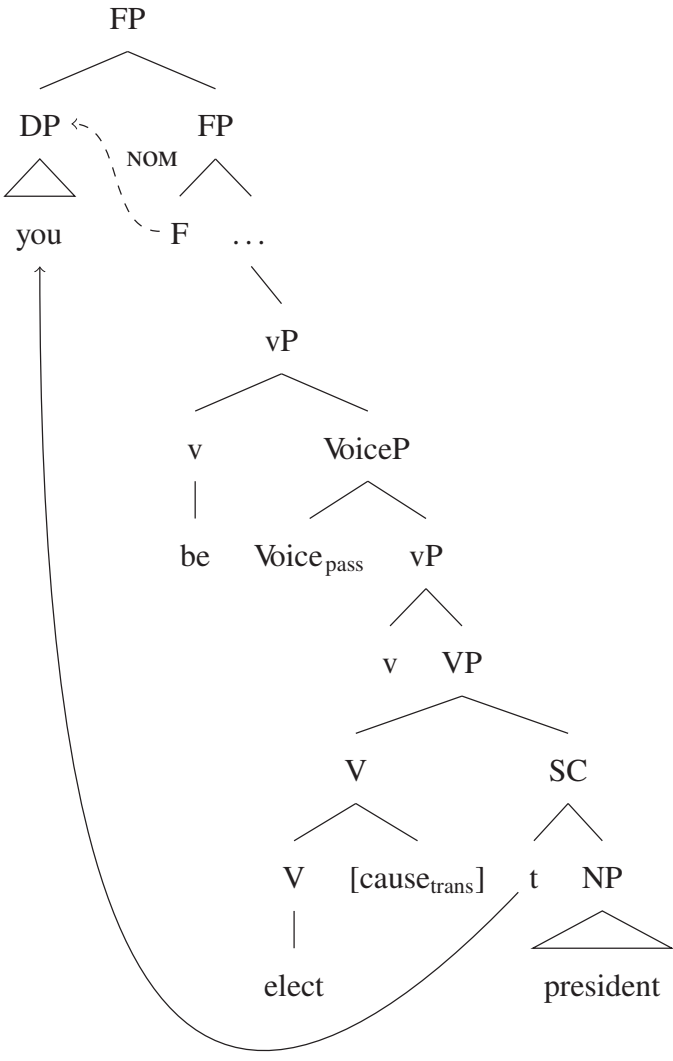


(53) (a) Be elected you president!

[Belfast A]

(b) $\mathrm{CP}$

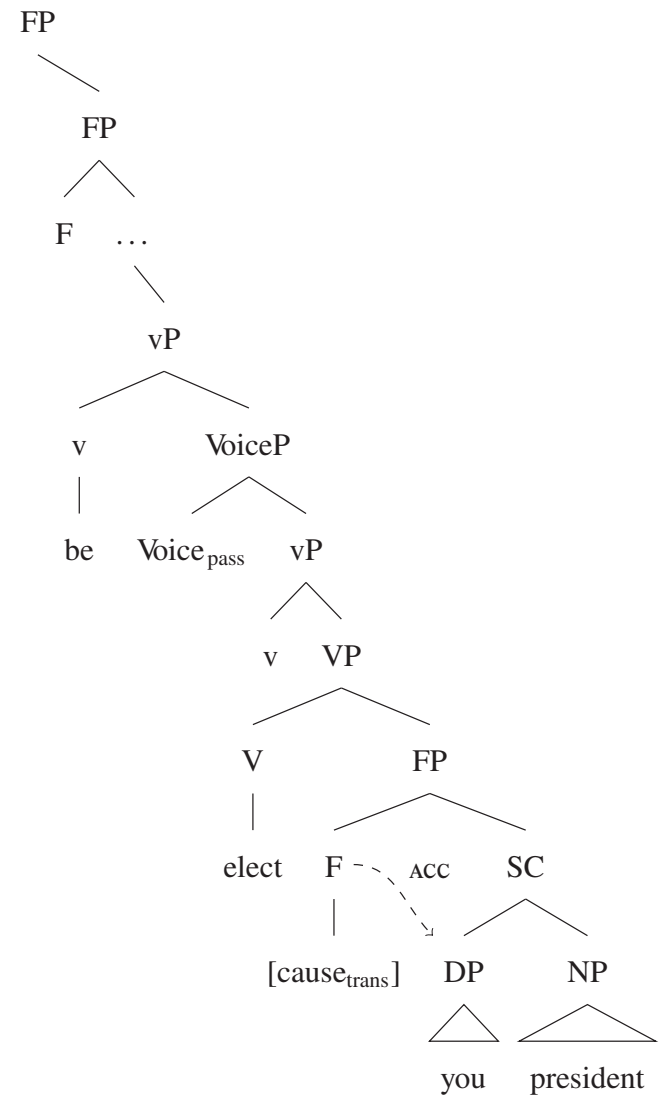

\subsection{Goal-PP constructions and resultatives}

Let us now return to verbs of motion. Suppose that these are always 'basically' unaccusative, that is, that they take an internal argument; they are the same semantic type as transitive verbs, but have no external argument introduced by a v head.

(54) $\quad \llbracket \operatorname{run} \rrbracket=\lambda x \cdot \lambda e \cdot \operatorname{run}(x)(e)$

Simple cases, with no PP, have the structure in (55a) and the interpretation in (55b). 
(55) John runs.

(a)

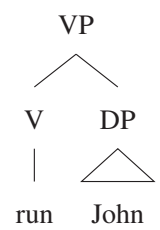

(b)

$$
\lambda e . \mathbf{r u n}(\mathrm{John})(e)
$$

As discussed above, many authors have argued that verbs of motion with goal-PP constructions are in fact resultative constructions, where the PP denotes something like a small clause. One important argument in favor of this treatment is again the behavior of again. With transitive verbs involving an (apparent) object and a goal PP, it is clear that again can take scope over a stative component alone (i.e. a restitutive reading):

(56) A cat I didn't know came in through the cat flap...

(a) $\quad \ldots$ so I threw the cat out again.

(b) \#... so again I threw the cat out.

In (56a), again must be taking semantic scope only over the cat out (as there hasn't been a previous throwing event). As before, this is sensitive to syntactic placement; the restitutive reading goes away in (56b). Beck (2005) notes that this is true also for intransitive goal-PP constructions.

(57) The unknown cat came in (to the house), and then...

(a) $\quad \ldots$ it ran out (of the house) again.

(b) \#... it again ran out of the house.

This suggests that, at some syntactic level, there is a constituent the cat out of the house which is being modified by again in (57a) (but not in (57b), where again takes scope over the whole verb phrase including ran).

To capture this, we can give verbs like run the same treatment as reviewed above for transitive verbs like elect. The valency-reducing causative shift can mediate between a PP small clause John to the park and the verb. 
(58)

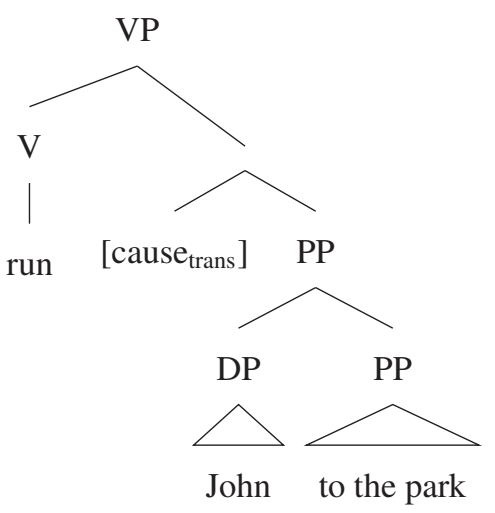

(59) (a) $\quad \llbracket \operatorname{run} \rrbracket=\lambda x \cdot \lambda e \cdot \operatorname{run}(x)(e)$

(b) $\llbracket$ John to the park $\rrbracket=\lambda s \cdot$ at $(\operatorname{park})(\mathbf{J o h n})(s)^{13}$

(c) $\llbracket$ run [cause trans $\left._{1}\right][$ John to the park] $\rrbracket=\lambda e \cdot \exists s \cdot$ at $($ park $)($ John $)(s) \&$ cause $(s)(e) \& \operatorname{run}(l x$. figure $(x)(s))(e)$ $=\lambda e . \exists s \cdot \operatorname{at}($ park $)($ John $)(s) \&$ cause $(s)(e) \& \operatorname{run}(\mathrm{John})(e)$ 'a running event which causes a state of John being at the park and whose theme is the figure of that end-state (i.e. John)'

If this is right, then we capture the differing behavior of goal-PP constructions in imperatives in Belfast A and in standard English in the same way as above for passive transitive resultatives such as elect $X$ president: [cause trans] $_{\text {] }}$ is merged in a functional head above the small clause in Belfast A, but merged directly onto the verb in standard English, leading to a difference in Case assignment possibilities. Apparent subjects - not syntactic arguments of the verb, but rather subjects of the PP small clause - can remain in situ in Belfast A, (60), as they can receive Case from [cause trans $_{\text {; }}$; but they must raise in standard English to receive Case.

[13] Along with Beck (2005), I take directional PPs to essentially denote the resultant state of the movement, i.e. to have a semantics similar to at. This is, of course, not quite right (see Beck 2005: 35-36 for discussion and a more sophisticated treatment of to), but will be adopted as a simplification for current purposes. 
(60) (a) Run you to the park. [Belfast A]

(b) $\mathrm{CP}$

FP<smiles>C1CC2CCCC2C1</smiles><smiles>FCP</smiles>

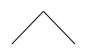

V VP
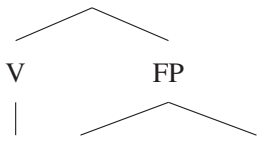

run $\mathrm{F}-\mathrm{ACC} \quad \mathrm{PP}$

[cause trans $\left._{\text {c }}\right] \quad \mathrm{DP} \quad \mathrm{PP}$

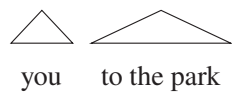

(61) (a) *Run you to the park./You run to the park.

(b)
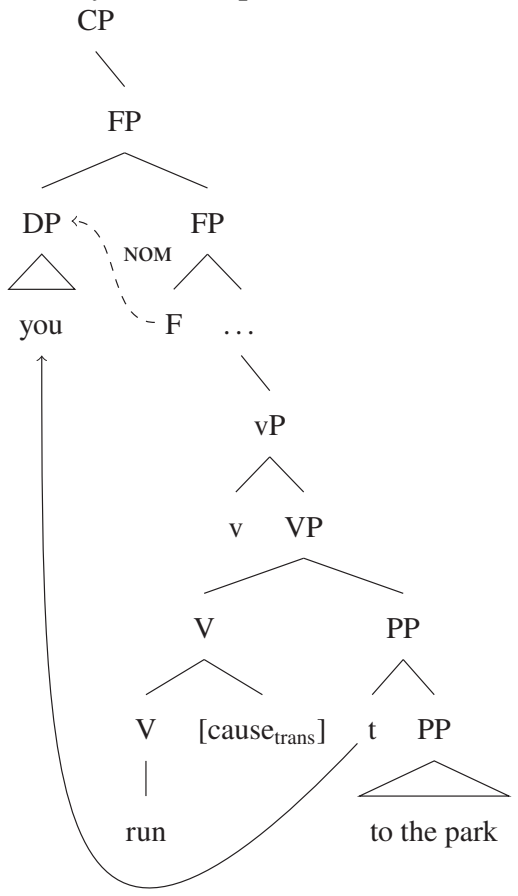
Note that this analysis correctly rules out postverbal imperative subjects even in Belfast A without a goal-PP or other small clause. In (62), there is no small clause (and no [cause trans $_{\text {] }}$ ) to assign Case; while in (63), the locative PP does not denote a resultant state of the running, and so would not be composed with the verb via

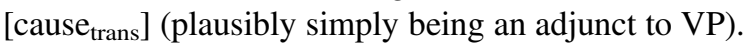

(62) (a) You run./*Run you.

(b) $\quad \mathrm{VP}$

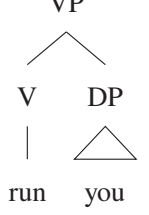

(no source of Case for you, raising forced)

(63) (a) You run in the park./*Run you in the park.

(b)

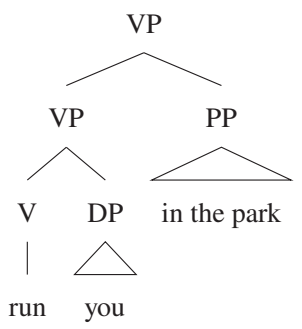

(no source of Case for you, raising forced)

The cases left to consider are verbs like arrive and leave, which have directionality 'built in' to them, and which allow postverbal subjects in Belfast A:

(64) (Repeated from (23))

(a) Arrive you before six o'clock.

(b) Leave you now.

[Belfast A; Henry 1995: 53]

The verbs arrive and leave do not combine with goal PPs (but rather only locative ones: arrive at the party, *arrive to the party). However, such verbs have in fact been argued by Moro (1997) and Hale \& Keyser (2000) to combine with a small clause, a covert PP.

(65) (a) [VP arrive [PP John there $]$

(b) [vP leave [PP John away]]

The covert there/away which I indicate in (65) may be an instantiation of Kayne's (2007) abstract PLACE (see also Collins 2007). Moro (1997) proposes the syntax in (65) as an explanation for the grammaticality of there-insertion with verbs like arrive (There arrived many students); there is an overt realization of the covert PP, 
which can raise to subject position. Note also the similar behavior of again in being able to take scope over the resultant state alone (i.e. a restitutive reading) - and the sensitivity to syntactic placement:

(66) The new students arrived...

(a) $\quad \ldots$ and then they left again. (i.e. they were once more not there)

(b) \#... and then they again left. (\# if they have never left before)

If arrive and leave introduce their subjects in (covert) PPs, the above behavior can be understood in terms of the constituent that again modifies.

(67) (a) [vP leave [[PP the students away] again]]

(restitutive, once more not there)

(b) [again [vP leave [PP the students away]]] (repetitive, a second leaving)

If this analysis of arrive and leave is correct, then this allows for the same treatment of postverbal imperative subjects as internal to a PP, and receiving Case from a functional head bearing [cause trans $_{\text {] }}$.

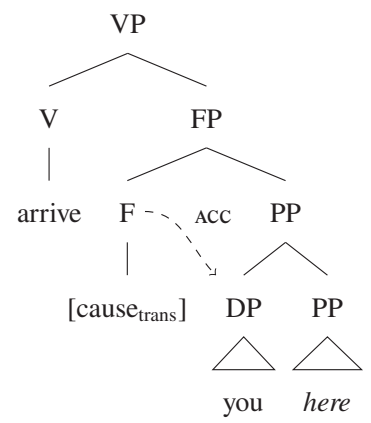

\subsection{Interim summary}

I have so far proposed that the distinction between Belfast English and standard English is not a general one concerning the movement of subjects, but rather concerns a difference in the structure of resultative constructions (including goal-PP constructions), and a concomitant difference in Case licensing between the two varieties. This proposal assumes that the (semantic) arguments of verbs like run can either be introduced as complements of the verb, or as the external argument of a PP. ${ }^{14}$

[14] As an anonymous reviewer emphasizes, this proposal potentially has deeper ramifications for the analysis of unaccusative verbs and the phenomenon of (variable) unaccusativity; see also Footnote 9 on raising versus control in goal-PP constructions. For reasons of space, I cannot follow up all of these potential ramifications here, including the interactions with, e.g., telicity or issues of auxiliary selection (see e.g., Sorace 2000), but this may be an important topic for future work. 
The reader might wonder if there is a simpler possibility for encoding the difference between standard and Belfast Englishes on this account: rather than suggesting a different geometry for resultative constructions (i.e. a different position for

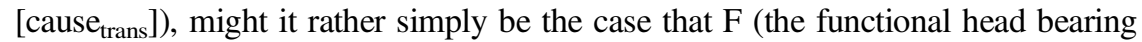

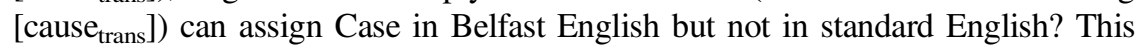
would be an 'uninteresting' stipulation, but the position of [cause trans] $_{\text {] }}$ is also a stipulation. I argue, however, that locating the difference in the position (and order of application of arguments) of [cause trans $_{\text {] }}$ allows the analysis to naturally extend to capture the more restricted patterns of postverbal imperative subjects seen in Scottish English. The remainder of the paper takes up the task of showing this.

\section{Scottish English in MORE Detail}

Recall that, in Scottish English, some - but very few - verbs allowed postverbal subjects in imperatives.

(69) (a) Away/get/clear off you to school.

(b) *Go/run you to school.

(c) *Be elected you president.

(d) *Eat you your dinner.

[ScotE]

The example in (69d), with the transitive verb eat, is ruled out presumably because the subject (as an external argument) is always structurally superior to the verb. However, if the subject in $(69 \mathrm{~b}, \mathrm{c})$ is underlyingly the subject of a resultative small clause/PP, then this suggests that this subject cannot receive Case in $(69 b, c)$ in Scottish English. If the analysis presented in the previous section is on the right track, this suggests that the general structure of (transitive) resultatives (including goal-PP constructions) in Scottish English involves merging [cause trans $_{\text {] }}$ onto the verb, not as a separate head above the small clause which can assign Case to its subject. That is, Scottish English (like standard English, and unlike Belfast A) only has the version of [cause trans $_{\text {] which }}$ combines, first, with the transitive verb (the relation between entities and events) and, second, with the small clause (the property of states). But what then is the explanation for the postverbal subject placement in (69a)? I propose that the key clue is to be found in a detailed examination of the apparently 'verbless' case with away.

\subsection{Away}

'Verbless' away is quite generally available in contexts where a bare verb can appear (the 'bare stem condition' of Carden \& Pesetsky 1977). ${ }^{15}$

[15] This distinguishes Scottish English from Henry's 'Belfast B' dialect (Henry 1995: 58-59, 77), in which 'verbless' away is grammatical in (postverbal subject) imperatives like Away you to bed, but does not appear in declaratives. I will not try to give an account of this aspect of variation here.

Constructions with a PP but no overt verb are of course familiar from older varieties of English as well as other present-day Germanic varieties: 
(70) (a) I'll away to school. (= I'll get away to school, leave for school)

(b) I'll have to away. (= have to leave)

(c) Will he just away to the pub? (= go to the pub, head off to the pub)

(d) He won't just away to the pub, don't worry.

[ScotE]

It cannot, however, appear in contexts where it would have to bear inflection. The examples in (71) are ungrammatical:

(71) (a) *He awayed to school.

(b) *He aways to school.

(c) *Has he awayed to school?

[ScotE]

And verbless away is most widely accepted in construction with 'filled T', i.e. in construction with an auxiliary (other than have):

(72) (a) He'll away to school.

(b) He didn't away to school.

(c) Did he really just away to the pub?

My own idiolect accepts the construction in infinitival contexts (73a), but only very marginally in uninflected finite contexts lacking an auxiliary or modal (73b, c); an anonymous reviewer, and Gary Thoms (p.c.; from the west of Scotland), report that all of the forms in (73) are more severely degraded or ungrammatical for them.

(73) (a) I'd prefer to just away to the pub.

(b) ?I away to work at 8 am every morning.

(c) ??If I away before the boss, there'll be problems.

[ScotE; my judgments]

Importantly, the construction requires a volitional or animate subject; (74a, b) are acceptable, but (74c) is degraded, and (74d) is impossible (and contrasts with the fully acceptable These problems just won't go away).

(74) (a) I'll away (to school).

(b) The cat will away (to its bed).

(c) ??The packages will away (to the post office) tomorrow.

(d) \#These problems just won't away.

$[\mathrm{ScotE}]$

(i) (a) The moon shines fair; you may away by night. (Shakespeare, Henry IV Part 1, act 3, scene 1 , line 136)

(b) I'll back to the Duke of Gloucester. (Shakespeare, Richard III, act 1, scene 4, line 110)

(c) If thou deny it, I will back to hell. (Marlowe, Doctor Faustus (c. 1588), scene 5, line 40)

I do not try to investigate the properties of the historical English pattern here. 
This distinguishes this Scottish English case from the general case of null motion verbs familiar from Germanic (75), which can (75a) but need not (75b, c, d) have animate/volitional subjects.

(75) (a) Ik moet weg.

I must away

'I have to leave.'

(b) Die doos kan naar de zolder.

[Dutch]

that box can to the attic

'That box can be put in the attic.' [Dutch, Van Riemsdijk 2002: 144]

(c) Pengene må ned i sekken.

money-the must down into bag-the

'The money must be put into the bag.'

[Norwegian, Wilder 2008: 239]

(d) Åttitalsfølelsen på badet bør bort før du selger eighties-feeling in bathroom-the should away before you sell huset

house-the

'You should get rid of the 80s feeling in the bathroom before you sell the house.' (lit. 'The 80 s feeling in the bathroom should away before you sell the house.')

[Norwegian; Anne Dahl p.c.]

This agency restriction provides, I believe, the key to the analysis of these structures. Suppose that Scottish English (but not standard English) has in its lexicon a null verb, similar to the null motion verbs in Germanic more generally (see e.g., Van Riemsdijk 2002), and like these null verbs in Germanic obligatorily selecting for a goal PP, but without any semantics of its own; it is a simple identity function, passing up the value of the goal PP it takes as complement. ${ }^{16}$

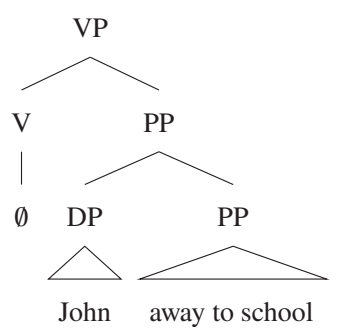

[16] notAtOrigo in (77b) is an ad hoc representation of the deictic contribution of away with respect to the speaker/reference point. 
(77)
(a) $\quad \llbracket \emptyset_{\mathrm{V}} \rrbracket=\lambda \phi . \phi$
(b) $\llbracket(76) \rrbracket=\llbracket$ John away to school $\rrbracket=\lambda s \cdot \mathbf{a t}(\mathbf{J o h n})(\operatorname{school})(s) \&$ notAtOrigo $(s)$

Now suppose that the little $\mathrm{v}$ head $\mathrm{v}_{\mathrm{ag}}$ which introduces external arguments, agents (Kratzer 1996), is merged above this structure.

(a)

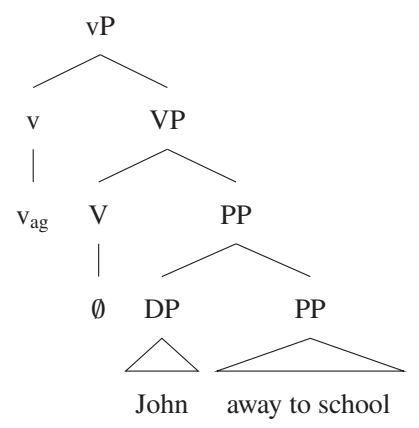

(b) $\quad \llbracket \mathrm{v}_{\mathrm{ag}} \rrbracket=\lambda x \cdot \lambda e \cdot \operatorname{agent}(x)(e)$

The denotation in (78b) and that in (77b) cannot combine as they are - but they are the right types for combination by [cause trans$_{\text {] }}$. The types are the same as an unaccusative or transitive verb combining with a small clause, exactly the case we have been considering. What is the result if we let [cause trans $_{\text {- }}$ - the standard English version which combines first with the verb - merge with little $\mathrm{v}$ in this structure? Semantically, the result is as below:

(a) $\quad\left[\mathrm{v}_{\mathrm{ag}}\left[\right.\right.$ cause $\left._{\text {trans }}\right] \rrbracket=\lambda P P_{\langle\mathrm{s}, \mathrm{t}\rangle} \cdot \lambda e \cdot \exists s \cdot P(s) \& \operatorname{cause}(s)(e) \&$ agent $(l y$.figure $(y)(s))(e)$

(b) $\quad\left[\left[\mathrm{v}_{\mathrm{ag}}\left[\right.\right.\right.$ cause $\left.\left._{\text {trans }}\right]\right][\mathrm{vP}$ John away to school] $]=\lambda e . \exists s \cdot \mathbf{a t}(\mathbf{J o h n})(\mathbf{s c h o o l})(s)$ \& notAtOrigo $(s) \&$ cause $(s)(e) \& \operatorname{agent}(l y$. figure $(y)(s))(e)$ $=\lambda e . \exists s \cdot \mathbf{a t}(\mathbf{J o h n})(\mathbf{s c h o o l})(s) \& \operatorname{notAtOrigo}(s) \& \operatorname{cause}(s)(e) \&$ agent $($ John $)(e)$

The $v_{a g}$ head in (79a) has been changed to the right type to combine with the small clause - and it has also had its valency reduced, so it will no longer semantically introduce an agent in its specifier. The agent is rather identified with the subject of the small clause. In (79b), we see the result of the whole composition: a description of events of John (agentively) causing John to be at school (which is not near the origo/reference point, i.e. it is 'away'). This is a fairly good paraphrase of the desired truth conditions. In particular, the fact that $\mathrm{v}_{\mathrm{ag}}$ has an agentive semantics means that 
the structure in (79) will be incompatible with non-agentive arguments, capturing the pattern in (74).

Suppose further that the particle away raises to adjoin to V (see Svenonius 1992).

(80)

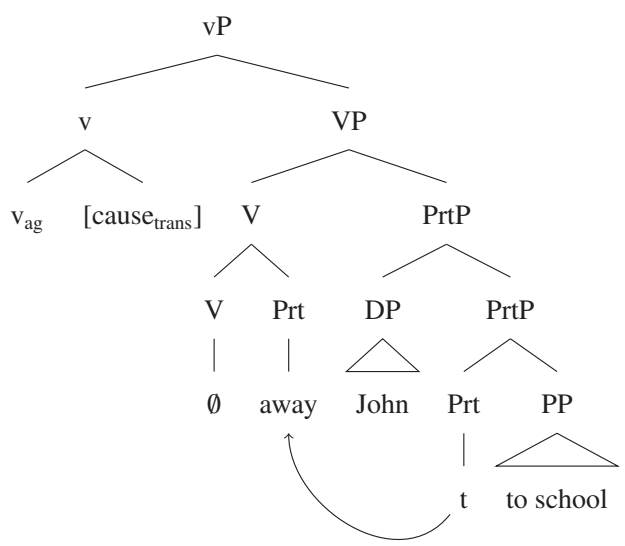

We can then suppose that - in the declarative case - TP is merged above this vP, and the EPP prompts movement of the subject (here John) to [Spec, TP].

(81) (a) John will away to school.

(b)

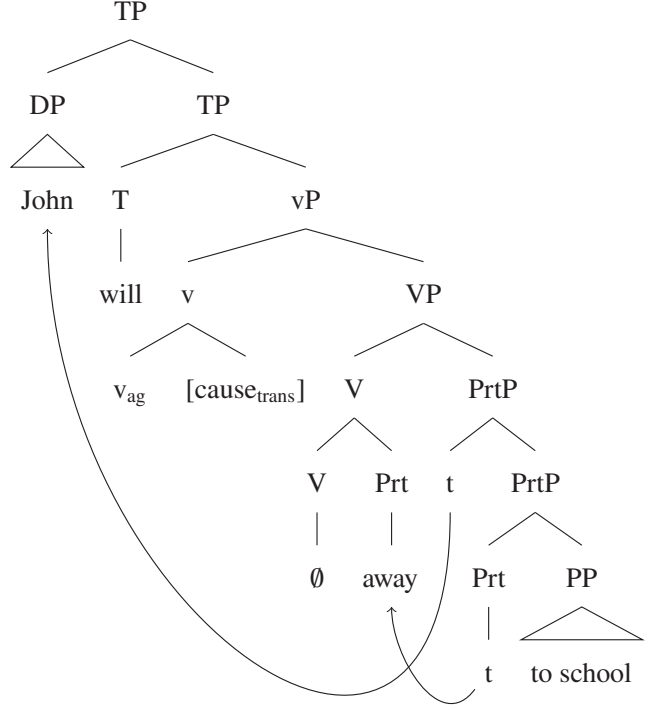


We are now in a position to return to post-'verbal' imperative subjects with away:

(82) Away you to school.

$[\mathrm{ScotE}]$

The key point here is that, on the present analysis, these structures contain $\mathrm{v}_{\mathrm{ag}}$, the head which standardly introduces external arguments and which assigns Case to objects. Even though this head has semantically had its valency reduced (has had its argument saturated), we might suggest that its ability to assign Case remains. As such, it can assign Case downwards to the subject within the PP/small clause.

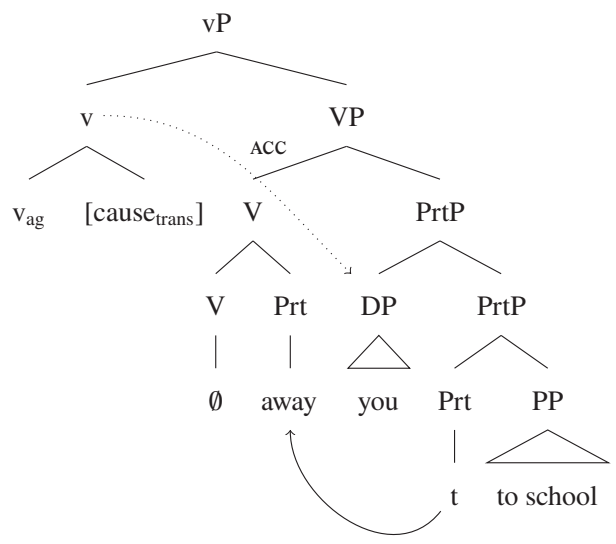

The crucial difference between Scottish English and standard English on this

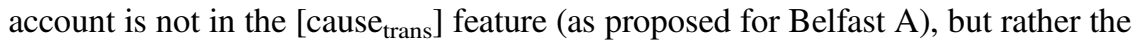
existence in Scottish English of a null verb, with no semantics of its own, which can combine with a goal PP.

Some comment is required on the distribution of this null V. As discussed above, away-constructions generally require a 'filled $\mathrm{T}$ '. This again seems familiar from the 'standard' Germanic case, when compared, e.g., with the proposal by Van Riemsdijk (2002) that ellipsis of $g o$ is licensed by modals. However, not only modals but also forms of $d o$ (in negation or question contexts) permit away in Scottish English. A simple explanation for the distribution of away/the null V may be that neither the null V, nor away, can morphologically host tense/agreement or aspectual morphology (i.e. forms like awayed or aways are not possible). ${ }^{17}$ Without a host for this morphology, it will be impossible to use away in finite

[17] Although an anonymous reviewer, citing Macafee (1980), notes that forms like the below are attested in some dialects of Scottish English (although obsolescing):

(i) (a) I ons the coat.

(b) I offs the shoes.

I will not try to account for forms like this here. 
contexts, or as a perfect participle, as this would violate the Stranded Affix Filter (Lasnik 1981). ${ }^{18}$ If there would in any case be no overt agreement (first/second person or plural subjects in simple present), the result is degraded but not fully ungrammatical (in my judgment; as noted above, others reject these more strongly):

(84) (a) ?I away to my work at 8 a.m. every day.

(b) ??They away to school.

The degradation seems to be an effect (for which I do not have an explanation) of the habitual meaning of the simple present, as these sentences are similarly degraded in question forms with $d o:^{19}$

(85) (a) ?Do you away to work at 8 a.m. every day?

(b) ??Do they away to school?

Speakers vary in their acceptance of infinitival complements like (86):

(86) \%I told the children to away to their beds.

I do not have a full explanation for this, but speculate that the variation may have something to do with how the different idiolects treat the morphophonological properties of infinitival to (cf., for example, the variation in judgments in whether/in what configurations to licenses VP Ellipsis discussed by Johnson 2001).

The null verb seems to be restricted to selecting PPs headed by away in the author's idiolect, as the structures in (87) are ungrammatical in that idiolect.
(a) ??I'll back to my bed.
(b) ??I'll off to my bed.

[18] Note that $d o$-support (in positive declaratives) cannot be used as a 'last resort' to give tense morphology a host, as it can in verb phrase ellipsis for example. The away-sentence in (i) is grammatical as such, but only on an 'emphatic'/polarity focus reading for did.

(i) \#He did away to his bed.

I do not know why do-support cannot be used in cases like (i), but note also the same effect obtains in other cases of the 'bare stem condition' such as the come/go V construction (Jaeggli \& Hyams 1993):

(ii) (a) He'll go get the shopping.

(b) *He goes gets the shopping.

(c) \#He did go get the shopping. (only emphatic did)

I put this aside as a mystery for analyses of $d o$-support rather than for the present analysis; see Jaeggli \& Hyams (1993) for some discussion.

[19] This may in some way be related to the apparent degradation of get forms with adverbs like always noted in Footnote 7. 
(c) ??I'll down to the shops.

(d) ?*I'll to my bed.

(e) *I'll into the school.

[ScotE]

This can potentially be treated as a restriction on spellout (anticipating the discussion of get below). The spellout of the verb as zero may be dependent on a form of formal licensing, the incorporation of the particle into the null $\mathrm{V} .{ }^{20} \mathrm{In}$ the idiolect under investigation here, only away can perform this function, but there is a certain amount of dialectal/idiolectal variation. An anonymous reviewer states that they accept (87b) with off, and the example in (88) with along is attested:

(88) I'll along to Dens and give the boys support.

('Murray's In No Hurry to Walk Out', Daily Record (Glasgow), February

27, 2013; Dens (Park) is a football stadium in Dundee.)

And a few examples can be found online which seem to lack a particle, consisting solely of a directional PP headed by to (in its dialectal form tae in (89)), although these are rare.

(89) The Belgians can tae fuck, no way better than curly fries and chips! (found on Twitter; tae fuck $\approx$ 'to hell')

The existence of forms like (89) suggests that, for some Scottish English speakers, the null motion verb does not need to be licensed via incorporation of a particle.

\subsection{Get}

The analysis above can now be extended to postverbal subjects with get.

(90) Get you to school.

$[\mathrm{ScotE}]$

This can be treated as the spellout of the null motion verb ${ }^{21}$ in the case where no particle raises to adjoin to it. The structure of (90) would then be as in (91) below. ${ }^{22}$

[20] We might compare this to the proposal that null Ps can be licensed by incorporation into overt Vs (Den Dikken 2010, extended to various cases in dialectal English by Myler 2013 and Bailey 2019); the Scots phenomenon may be the 'inverse' of this.

[21] Or possibly of the complex $\mathrm{v}_{\mathrm{ag}}+\left[\right.$ cause $\left._{\text {trans }}\right]+\emptyset_{\mathrm{V}}$, assuming that the null motion $\mathrm{V}$ moves to $\mathrm{v}_{\mathrm{ag}}$. Den Dikken (2010) presents an analysis in which an abstract (inchoative) verb, which he notates as GET, forms the core of motion verb constructions and combines with a small-clause-like PP in a similar way to that outlined here. However, for Den Dikken, this abstract head underlies a wide variety of manner-of-motion verbs, not the much more restricted set considered here.

[22] The notion that this version of get assigns accusative case may receive support from earlier stages of English (as noted in Footnote 2): while the case is not morphologically visible in modern English, the Shakespearean example Get thee to a nunnery shows accusative case thee (rather than nominative thou). It is difficult to draw firm conclusions here, however, as it is possible that this thee is a reflexive form (co-occurring with a null subject), i.e. that this example corresponds to modern English Get yourself to a nunnery. 
(91)

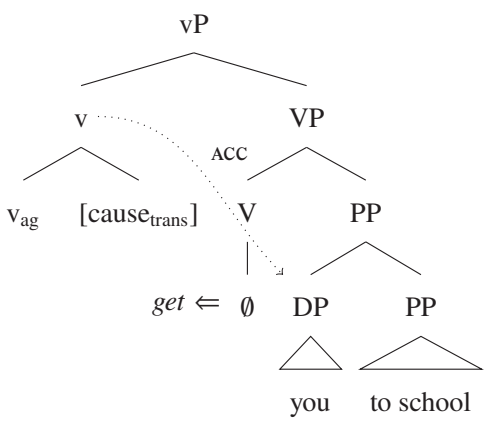

This is not quite the same get as appears in motion constructions in standard English (92), both for reasons internal to the analysis - the null, 'semanticsless' motion verb in (91) is hypothesized to not be available in standard English - and also because the 'standard' get can be non-agentive (92b); the get in (91) requires the presence of ([cause trans $_{\text {t-marked) }} \mathrm{v}_{\mathrm{ag}}$ for its interpretation, which should force an agentive interpretation.

(92) (a) Mary got to school.

(b) The parcels got to their destination.

We can perhaps rather analyze the get in (92) as the spellout of a V head with the

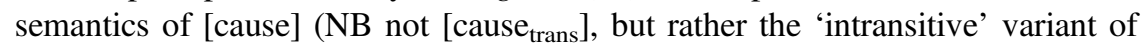
[cause] described in (45a)).

(93) (a)

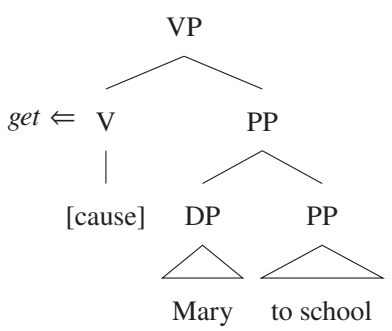

(b)

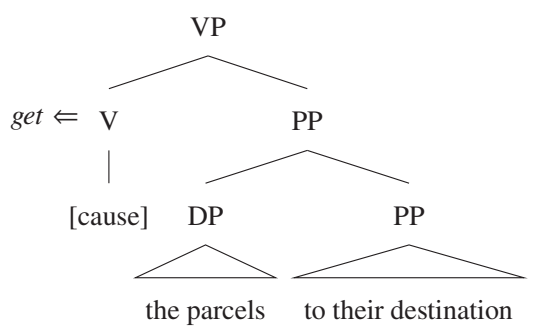


(a) $\llbracket(93 \mathrm{a}) \rrbracket=\lambda e . \exists s$.at $($ school $)($ Mary $)(s) \&$ cause $(s)(e)$

(b) $\llbracket(93 \mathrm{~b}) \rrbracket=\lambda e . \exists s$. at $($ destination $)($ parcels $)(s) \&$ cause $(s)(e)$

No agentive semantics is implied in (94), as desired. Separating this get from the get which allows postverbal subjects in Scottish English also accounts for the fact that the 'standard' get (in (92)) can itself be causativized - that is, it can have an additional external argument, as in (95).

(95) (a) Her mum got Mary to school.

(b) The courier got the parcels to their destination.

On the current analysis, this can be captured by merging a $\mathrm{v}_{\mathrm{ag}}$ head above the VPs in (93) (see Alexiadou, Anagnostopoulou \& Schäfer 2006).

(a)

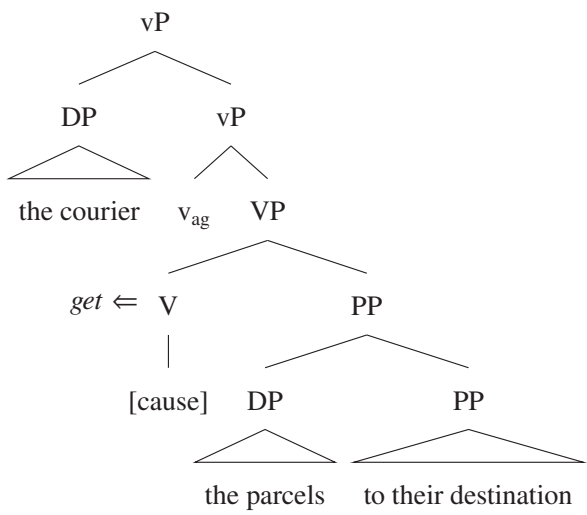

(b) $\quad(96 \mathrm{a}) \rrbracket=\lambda e . \exists s$.at $($ destination $)($ parcels $)(s) \&$ cause $(s)(e) \&$ agent (courier) $(e)$

Such causativization can also be reflexive, as in (97).

(97) He got himself to school.

Importantly, causativization is not possible with motion away. ${ }^{23}$

(98) (a) *I'll away myself/him to school.

(b) *Away yourself to school./*You away yourself to school.

That can be understood if away has the $\mathrm{v}_{\mathrm{ag}}+\left[\right.$ cause $\left.\mathrm{trans}_{\text {s }}\right]$ structure suggested in Section 4.1; the structure in (99) can be built, but on the assumption that only one $v_{a g}$

[23] Thanks to an anonymous reviewer for pointing out the importance of these data and of distinguishing the two gets. 
can be present in any one clause, it would not be possible to introduce another external argument (and semantically no external argument can be introduced in the specifier of $v_{a g}$ in (99), as it has been 'detransitivized' by [cause trans $_{\text {] }}$ ).

(99) (Repeated from (80))

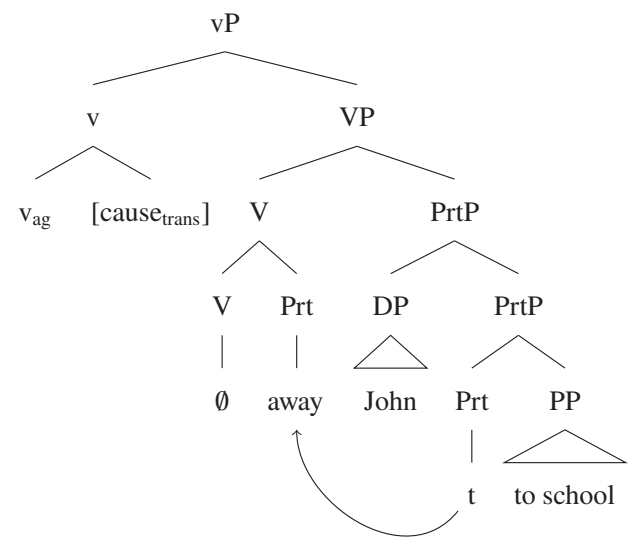

Distinguishing the two gets also gives us a handle on why it is ONLY motion get which allows for a postverbal subject in Scottish English. The below are not grammatical, at least in the author's idiolect.

(100) (a) *Get you promoted.

(b) *Get you drunk.

(c) *Get you a new car.

The get in (100a, b) is plausibly the same get as in (92) (the possession get in (100c) presumably being something different again). Importantly, there is no external argument, and therefore no $\mathrm{v}_{\mathrm{ag}}$, in such structures (when only one argument is present).

(101) $\quad(=(100 b))$

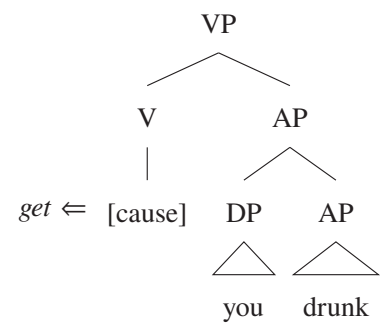


There would therefore be no source of Case for the postverbal subjects in (101), and such structures are therefore ruled out, given the additional stipulation that Scottish English (like other Germanic languages) allows the null verb to combine only with a goal PP. ${ }^{24}$

\subsection{Taboo off verbs}

A similar analysis can be given to the 'taboo off verbs:

(102) $\{$ Clear/Buzz/Shove/Bugger/Piss/Sod/Fuck $\}$ off you back home. [ScotE]

With the possible partial exception of clear, none of the verbs that appear in (102) have the meaning that they do outside of this construction. Rather, all the verbs in (102) seem to have very little meaning of their own besides an expressive dimension (i.e. they are 'taboo'). Given this, I suggest that is plausible that these verbs (in Scottish English) also have the truth-conditional semantics of an identity function, as with the null motion verb above. For simplicity, I show their expressive component as a presupposition (between the lambdas in (103) and the output, a condition on well-definedness), though in a fuller treatment, this would presumably be encoded as something like a conventional implicature (see Potts 2005). These select PrtPs headed by off (prompting raising of off to the verb ${ }^{25}$ ), and pass up the meaning of these PrtPs (i.e. properties of states).

[24] This makes the prediction that there may be some dialects of English that allow forms like Get you drunk; these would be dialects that allow for a null verb to combine not just with a goal PP but with any small clause.

(i) $\left[\mathrm{vP}_{\mathrm{ag}}+\left[\right.\right.$ cause $\left._{\text {trans }}\right]\left[\mathrm{vP} \emptyset_{\mathrm{V}}[\mathrm{sc}\right.$ you drunk $\left.\left.]\right]\right]$

However, transitive forms like get you a new car should only be possible in dialects which generally allow postverbal transitive subjects (e.g., Belfast B), as its subject is not introduced in a small clause. That is, no dialect is predicted to allow (100c), but not allow, e.g., Eat you your dinner. However, the matter may be somewhat empirically confused to the extent that some varieties (e.g., some American dialects) may allow anaphoric pronouns without overt reflexive marking in INDIRECT object position (personal dative constructions of the type I got me a car, see e.g., Webelhuth \& Dannenberg 2006; Horn 2008); such structures would then allow for imperatives like Get you a new car - but you here would be the indirect object, not the subject. Cf. also Footnote 22.

[25] Apparently obligatorily. For this author, the word order??Bugger you off back home is degraded, and while internet searches do reveal instances of the word order Bugger you off, it is not clear whether this might be an instance of verb-raising to $\mathrm{C}$. I do not have a full explanation for this restriction, but it may again be connected to spellout in a low-level way: if bugger etc. are (in this context) spellout options for the null verb $\emptyset_{\mathrm{V}}$, then they might only be specified for this spellout if off raises, i.e. a rule of the form $\emptyset_{\mathrm{V}}+[$ taboo $] \rightarrow$ bugger $/\left[\mathrm{v} \_\right.$off $]$. 
(103)

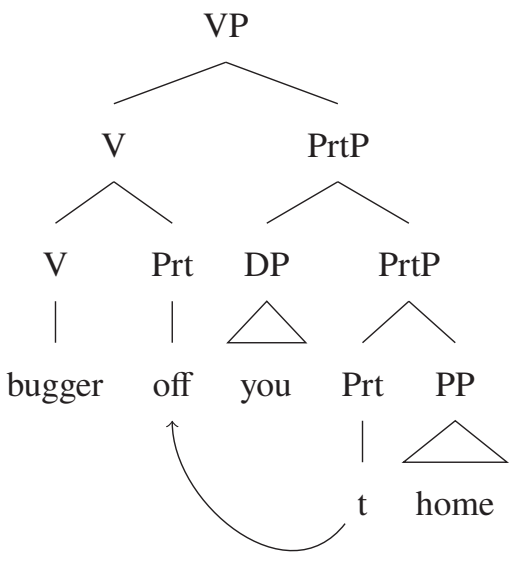

(104) (a) [bugger $\rrbracket=\lambda \phi$. the speaker is speaking coarsely . $\phi$

(b) $\llbracket$ you off home $\rrbracket=\lambda s$.atHome $($ you $)(s) \& \operatorname{notAtOrigo}(s)$

(c) $\llbracket(103) \rrbracket=\lambda s$. the speaker is speaking coarsely . atHome $($ you $)(s) \&$ notAtOrigo $(s)$

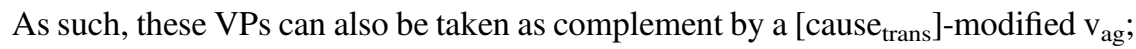
and as before, this allows for Case assignation to the subject of the PrtP in its underlying position in imperatives.

(105) (a) Bugger off you back home.

[ScotE]

(b)

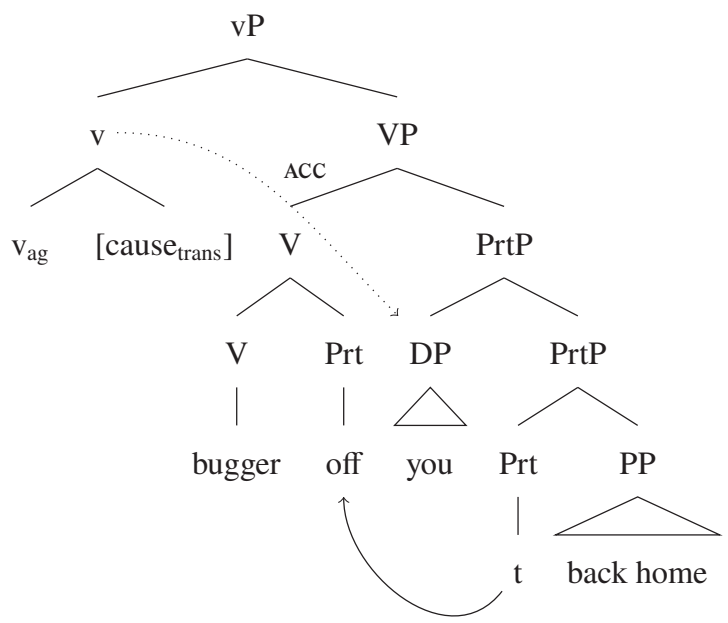


As with get, this correctly predicts that these verbs cannot be causativized (although see Footnote 27): ${ }^{26}$

(106) *He buggered himself off home.

I assume that Englishes in which postverbal subjects are not permitted with taboo off verbs treat them as 'normal' motion verbs, i.e. where the verb itself introduces an event argument and is modified by [cause trans $_{\text {] }}$. The absence of $\mathrm{v}_{\mathrm{ag}}$ in such structures means that the subject of the PP will have to raise for Case. ${ }^{27}$

(a) (Standard English)

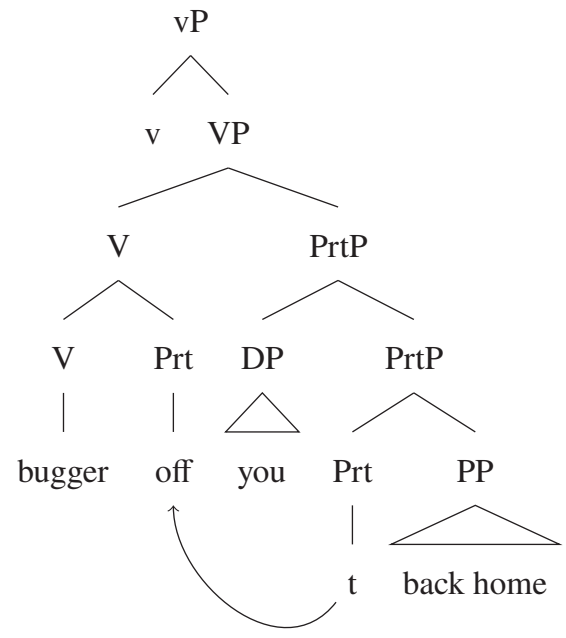

(no source of Case for you, raising forced)

(b) bugger $\rrbracket=\lambda x . \lambda e$. the speaker is speaking coarsely. move $(x)(e)$

[26] For some speakers, although not this author, there is a transitive usage for some of these verbs with the meaning 'to annoy' (That fucks me off); I assume this is separate from the motion use.

[27] The structure in (107a) would theoretically allow for $v_{a g}$ to be merged on top of it, giving rise to a causativized structure:

(i) (a) (*)He fucked himself off home.

(b) $(*)$ I buggered him off.

For speakers who find these ungrammatical, this is presumably for whatever reason path-based verbs of motion cannot generally be causativized (*I went the boy to school, intended 'I made him go'). But Google searches (for bugger/fuck + object pronoun + off) do in fact reveal a number of cases like (i) (where the sense is clearly one of caused motion). This could be simply encoded as a difference between speakers in the selectional restrictions of $\mathrm{v}_{\mathrm{ag}}$, though detailed exploration of this issue is beyond the scope of this paper. 


\subsection{Loose ends: mere and mon}

This subsection notes for completeness two other instances of apparently the same pattern, with reduced forms of come here and come on.

(108) (a) Mere you to the pub.

(b) Mon you to the pub.

$[\mathrm{ScotE}]$

Such forms seem to more-or-less transparently result from incorporation of the particles here and on into a heavily reduced form of the verb come. Some speakers (although not this author) also have a form gon, transparently 'go on' ${ }^{28}$

(109) Gon you to the shops.

These forms could potentially be given a similar analysis to the taboo off verbs, with the $(c)$ ' $m$ - and $g$-components being contributed by $\mathrm{V}$ and the particles raising to incorporate.

(110)

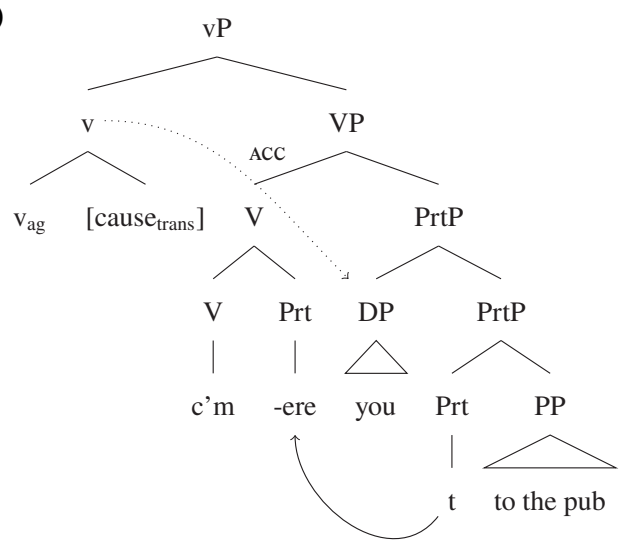

However the mere/mon forms seem to be restricted to imperatives; the following are not very natural (note that away has a similar restriction in Belfast English; see Footnote 15; see also Henry 1995: 58-59, 77).

(111) (a) ??You should mere to my place.

(b) ??You should mon over to the pub.

And in the relevant dialects which have gon, this also has a use as an exhortative particle in imperatives - see also McCloskey (1997) on a similar particle in Ulster English and Weir (2013) and Sailor \& Thoms (2019) on the similar particle gonnae in Scottish English:

[28] Thanks to Gary Thoms for judgments here. 
Gon you see who that is at the door.

Given the restriction to imperatives, these forms may be amenable to an alternative analysis; e.g., as being generated in or moved to C (see Weir 2013; Sailor \& Thoms 2019). As the facts here are somewhat less clear, the above data are included for completeness, but detailed analysis is left to future work.

\section{Conclusion}

The analysis laid out in this paper has aimed to capture the variation we see between standard, Belfast, and Scottish Englishes in a grammatically constrained way. Beyond simply capturing the data and the variation between dialects and speakers, the analysis presented here raises questions of wider theoretical import. If the analysis presented here is on the right track, it provides support for a view of goal-PP constructions in which they introduce their own external argument, as in Beck \& Snyder (2001) and Beck (2005), among others. Moreover, given that this external argument appears to be realized in situ in postverbal imperatives in Belfast and Scottish Englishes, this suggests (as suggested in Footnote 9) that goal-PP constructions are (or at least can be) raising constructions, rather than control structures in which the external argument is PRO, as proposed by previous authors.

Many avenues for further exploration remain. This exploration has focused on a limited set of data, i.e. the data reported in Henry (1995) for Belfast English, and a restricted set of Scottish English idiolects. The empirical picture is likely to be considerably richer than this suggests - as Henry's (1995) pioneering work already demonstrated, by showing the distinction between 'Belfast A' and 'Belfast B'. Given the close historical and geographical relationship between Belfast English(es) and Scottish English(es), diachronic and/or detailed microcomparative work on (the relation between) these varieties is likely to be fruitful. In addition, diachronic studies of the null verb construction in English, and of (motion) get with apparent postverbal argument (of the get thee to a nunnery type, cf. Footnotes 2 and 22), may shed light on the development of the Scottish and Belfast patterns, and the extent to which specifically get is 'special', as implied by the data and analysis in this paper.

\section{REFERENCES}

Adger, David \& Jennifer Smith. 2010. Variation in agreement: A lexical feature-based approach. Lingua $120.5,1109-1134$.

Alexiadou, Artemis, Elena Anagnostopoulou \& Florian Schäfer. 2006. The properties of anticausatives crosslinguistically. In Mara Frascarelli (ed.), Phases of interpretation, 187-212. Berlin/New York: Mouton de Gruyter.

Bailey, Laura R. 2019. Some characteristics of Southeast English preposition-dropping. Iberia 10, 48-70.

Beck, Sigrid. 2005. There and back again: A semantic analysis. Journal of Semantics 22.1, 3-51.

Beck, Sigrid \& William Snyder. 2001. Complex predicates and goal PPs: Evidence for a semantic parameter. In Anna H.-J. Do, Laura Domínguez \& Aimee Johansen (eds.), Proceedings of the Boston 
University Conference on Language Development (BUCLD) 25, 114-122. Somerville, MA: Cascadilla Press.

Beukema, Frits \& Peter Coopmans. 1989. A government-binding perspective on the imperative in English. Journal of Linguistics 25.2, 417-436.

Bowers, John. 1997. A binary analysis of resultatives. In R. C. Blight \& M. J Moosally (eds.), Texas Linguistic Forum 38, 43-58. Austin: University of Texas.

Carden, Guy \& David Pesetsky. 1977. Double-verb constructions, markedness, and a fake co-ordination. In Woodford A. Beach, Samuel E. Fox \& Shulamith Philosoph (eds.), Proceedings of the Chicago Linguistic Society (CLS) 13, 82-92. Chicago: CLS.

Carrier, Jill \& Janet H. Randall. 1992. The argument structure and syntactic structure of resultatives. Linguistic Inquiry 23.2, 173-234.

Chomsky, Noam. 1995. The minimalist program. Cambridge, MA: MIT Press.

Collins, Chris. 2007. Home sweet home. NYU Working Papers in Linguistics 1, 1-34.

Den Dikken, Marcel. 2010. Directions from the GET-GO: on the syntax of manner-of-motion verbs in directional constructions. Catalan Journal of Linguistics 9, 23-53.

Dowty, David. 1979. Word meaning and Montague Grammar. Dordrecht: Reidel.

Fodor, Janet D. 1972. Beware. Linguistic Inquiry 4.3, 528-535.

Folli, Raffaella \& Heidi Harley. 2006. On the licensing of causatives of directed motion: Waltzing Matilda all over. Studia Linguistica 60.2, 121-155.

Hale, Kenneth \& Samuel Jay Keyser. 2000. There-insertion unaccusatives. Ms., MIT. http://lingphil.mit. edu/papers/hale/papers/hale013.pdf.

Han, Chung-Hye. 2000. The structure and interpretation of imperatives: Mood and Force in Universal Grammar. New York: Garland.

Henry, Alison. 1995. Belfast English and standard English: Dialect variation and parameter setting. New York/Oxford: Oxford University Press.

Hoekstra, Teun. 1988. Small clause results. Lingua 74.2-3, 101-139.

Hoekstra, Teun \& Rene Mulder. 1990. Unergatives as copular verbs: Locational and existential predication. The Linguistic Review 7, 1-79.

Horn, Laurence R. 2008. I love me some him: The landscape of non-argument datives. Empirical Issues in Syntax and Semantics 7, 169-192.

Jaeggli, Osvaldo \& Nina M. Hyams. 1993. On the independence and interdependence of syntactic and morphological properties: English aspectual come and go. Natural Language and Linguistic Theory $11.2,313-346$.

Jamieson, E. 2015. An investigation of verb raising in the Shetlandic dialect of Scots. MA thesis, University of Edinburgh.

Johnson, Kyle. 2001. What VP ellipsis can do, and what it can't, but not why. In Mark Baltin \& Chris Collins (eds.), The handbook of contemporary syntactic theory, 439-479. Oxford: Blackwell.

Kayne, Richard. 2007. A short note on where vs. place. In R. Maschi, N. Penello \& P. Rizzolatti (eds.), Miscellanea di studi linguistici offerti a Laura Vanelli da amici e allievi padovani, 245-257. Udine: Forum.

Kratzer, Angelika. 1996. Severing the external argument from its verb. In Johan Rooryck \& Laurie Zaring (eds.), Phrase structure and the lexicon, 109-137. Dordrecht: Kluwer.

Kratzer, Angelika. 2005. Building resultatives. In Claudia Maienborn \& Angelika Wöllstein (eds.), Event arguments: Foundations and applications, 177-212. Tubingen: Max Niemeyer Verlag.

Lasnik, Howard. 1981. Restricting the theory of transformations. In Norbert Hornstein \& David Lightfoot (eds.), Explanation in linguistics, 152-173. London: Longmans.

Lewis, David. 1973. Causation. Journal of Philosophy 70.17, 556-567.

Macafee, Caroline. 1980. Characteristics of non-standard grammar in Scotland. Ms., University of Aberdeen.

McCloskey, James. 1997. Subjecthood and subject positions. In Liliane Haegeman (ed.), Elements of grammar, 197-235. Dordrecht: Kluwer.

Moro, Andrea. 1997. The raising of predicates: Predicative noun phrases and the theory of clause structure. Cambridge: Cambridge University Press. doi:10.1017/CBO9780511519956.

Myler, Neil. 2013. On coming the pub in the North West of England: Accusative unaccusatives, dependent case, and preposition incorporation. Journal of Comparative Germanic Linguistics 16.2-3, 189-207.

Pietsch, Lukas. 2005. Variable grammars: Verbal agreement in northern dialects of English. Berlin: De Gruyter. 
Platzack, Christer \& Inger Rosengren. 1998. On the subject of imperatives: A minimalist account of the imperative clause. Journal of Comparative Germanic Linguistics 1.3, 177-224.

Pollock, Jean-Yves. 1989. Verb movement, Universal Grammar, and the structure of IP. Linguistic Inquiry 20.3, 365-424.

Potts, Christopher. 2005. The logic of conventional implicatures. Oxford: Oxford University Press.

Ramchand, Gillian \& Peter Svenonius. 2002. The lexical syntax and lexical semantics of the verbparticle construction. In Line Mikkelsen \& Christopher Potts (eds.), Proceedings of the West Coast Conference on Formal Linguistics (WCCFL) 21, 101-114. Somerville, MA: Cascadilla Press.

Rupp, Laura. 2007. 'Inverted' imperatives. In Wim van der Wurff (ed.), Imperative clauses in generative grammar: Studies in honour of Frits Beukema (Linguistik Aktuell/Linguistics Today 103), Amsterdam: John Benjamins.

Sailor, Craig \& Gary Thoms. 2019. Exhortative clauses in Scots. Presentation at Edisyn 9 workshop, University of Glasgow. http://www.craigsailor.net/papers/edisyn_gonnae.pdf.

Smith, Jennifer. 2000. Synchrony and diachrony in the evolution of English: Evidence from Scots. Doctoral dissertation, University of York.

Sorace, Antonella. 2000. Gradients in auxiliary selection with intransitive verbs. Language 76.4, 859-890.

Svenonius, Peter. 1992. Movement of $\mathrm{P}^{0}$ in the English verb-particle construction. In H. Andrew Black \& James McCloskey (eds.), Syntax at Santa Cruz 1, 93-113. Santa Cruz, CA: Syntax Research Center, USCS.

Svenonius, Peter. 2003. Limits of P: Filling in holes vs. falling in holes. Nordlyd 31.2, 431-445.

Svenonius, Peter. 2007. Adpositions, particles, and the arguments they introduce. In Eric Reuland, Tanmoy Bhattacharya \& Giorgos Spathas (eds.), Argument structure, 66-103. Amsterdam: John Benjamins.

Svenonius, Peter. 2010. Spatial P in English. In Guglielmo Cinque \& Luigi Rizzi (eds.), Mapping spatial PPs: The cartography of syntactic structures, vol. 6, 127-160. Oxford: Oxford University Press.

Talmy, Leonard. 1978. Figure and ground in complex sentences. In Joseph H. Greenberg (ed.), Universals of human language, vol. 4, 625-649. Stanford, CA: Stanford University Press.

Van Hout, Angeliek. 2004. Unaccusativity as telicity checking. In Artemis Alexiadou, Elena Anagnostopoulou \& Martin Everaert (eds.), The unaccusativity puzzle: Studies on the lexicon-syntax interface, 332-353. Oxford: Oxford University Press.

Van Riemsdijk, Henk. 2002. The unbearable lightness of GOing: The projection parameter as a pure parameter governing the distribution of elliptic motion verbs in Germanic. Journal of Comparative Germanic Linguistics 5, 143-196.

Von Stechow, Arnim. 1995. Lexical decomposition in syntax. In Urs Egli, Peter E. Pause, Christoph Schwarze, Arnim von Stechow \& Götz Wienold (eds.), The lexicon in the organization of language, 81-118. Amsterdam: John Benjamins.

Von Stechow, Arnim. 1996. The different readings of wieder 'again': A structural account. Journal of Semantics 13.2, 87-138.

Webelhuth, Gert \& Clare J. Dannenberg. 2006. Southern American English personal datives: The theoretical significance of dialectal variation. American Speech 81.1, 31-55.

Weir, Andrew. 2013. The syntax of imperatives in Scots. In Janet Cruickshank \& Robert M. Millar (eds.), After the storm: Papers from the Forum for Research on the Languages of Scotland and Ulster, 261-285. Aberdeen: FRLSU.

Wilder, Christopher. 2008. The PP-with-DP construction. In Jacek Witkoś \& Gisbert Fanselow (eds.), Elements of Slavic and Germanic grammars: A comparative view, 235-253. Frankfurt am Main: Peter Lang.

Zanuttini, Raffaella. 1996. On the relevance of tense for sentential negation. In Luigi Rizzi \& Adriana Belletti (eds.), Parameters and functional heads, 181-207. Oxford: Oxford University Press.

Zanuttini, Raffaella, Miok Pak \& Paul Portner. 2012. A syntactic analysis of interpretive restrictions on imperative, promissive, and exhortative subjects. Natural Language and Linguistic Theory 30.4, $1231-1274$.

Author's address: $\quad$ NTNU - Norwegian University of Science and Technology, Department of Language and Literature, Dragvoll, 7491 Trondheim, Norway,

andrew.weir@ntnu.no 